\title{
A Review on Applications of CFD Modeling in COVID-19 Pandemic
}

\author{
Fateme Mohamadi ${ }^{1} \cdot$ Ali Fazeli $^{1}(\mathbb{D}$ \\ Received: 25 May 2021 / Accepted: 28 December 2021 / Published online: 20 January 2022 \\ (c) The Author(s) under exclusive licence to International Center for Numerical Methods in Engineering (CIMNE) 2022
}

\begin{abstract}
COVID-19 pandemic has started a big challenge to the world health and economy during recent years. Many efforts were made to use the computation fluid dynamic (CFD) approach in this pandemic. CFD was used to understanding the airborne dispersion and transmission of this virus in different situations and buildings. The effect of the different conditions of the ventilation was studied by the CFD modeling to discuss preventing the COVID-19 transmission. Social distancing and using the facial masks were also modeled by the CFD approach to study the effect on reducing dispersion of the microdroplets containing the virus. Most of these recent applications of the CFD were reviewed for COVID-19 in this article. Special applications of the CFD modeling such as COVID-19 microfluidic biosensors, and COVID-19 inactivation using UV radiation were also reviewed in this research. The main findings of each research were also summarized in a table to answer critical questions about the effectiveness levels of applying the COVID-19 health protocols. CFD applications for modeling of COVID-19 dispersion in an airplane cabin, an elevator, a small classroom, a supermarket, an operating room of a hospital, a restaurant, a hospital waiting room, and a children's recovery room in a hospital were discussed briefly in different scenarios. CFD modeling for studying the effect of social distancing with different spaces, using and not using facial masks, difference of sneezing and coughing, different inlet/outlet ventilation layouts, combining air-conditioning and sanitizing machine, and using general or local air-conditioning systems were reviewed.
\end{abstract}

\section{Introduction}

In late 2019, the COVID-19 virus outbreak began in Wuhan, China, causing the world to face, in a short time (by early 2020), a significant virus infection-related epidemic leading to an acute respiratory syndrome that could end in death if not treated properly [1]. The virus-caused global pandemic has not only affected people's lives severely all over the world but has also damaged the countries' economies. Like many other infectious diseases (e.g., flu), this virus can transfer through the air and affect the world's population; so far it has killed thousands of people. Different countries have thought of different mechanisms to control this virus [2]. According to the WHO, the coronavirus is transferable through coughing/sneezing respiratory droplets larger than $5 \mu \mathrm{m}[3,4]$. Researches have also been done on whether the transfer is possible through smaller particles in the air [5].

Ali Fazeli

alifazeli@ut.ac.ir

1 Department of Chemical Engineering, Caspian Faculty of Engineering, College of Engineering, University of Tehran, Tehran, Iran
Growing evidence found in airborne particles by detecting the RNAs of the SARS-CoV-2 virus plus studies on how many hours it can survive in the air show that through-theair-transfer is quite possible [6,7]. The upper respiratory tract evidence of asymptomatic people infected with the COVID-19 virus has raised the hypothesis that these people's respiratory microparticles due to their normal activities (e.g., talking) can greatly cause the virus to spread in the air $[8,9]$. Considering the very high air-transferability of the virus, the healthcare personnel, who are in constant direct/indirect contact with infected patients, are at high risk and, hence, measures are to be taken to properly ventilate the air inside the hospitals' infectious wards to protect them [10-13]. The rapid disease spreading has caused some cities to begin, in response to the lack of medical centers, to build temporary hospitals for the centralized treatment of patients with acute respiratory syndromes [14]. Such hospital spaces need special exhausts in their air conditioning systems to evacuate the harmful air produced by patients [15]. Unlike other particles, as pathogens are very small with diameters not more than $100 \mathrm{~nm}$, they move under the influence of air particles and, hence, their movement paths are hard to analyze. Computer science advances solved 
this problem using a computational fluid dynamics (CFD)based method and developed it well over the years. The CFD solution of nonlinear Navier-Stokes equations enables very complex fluid flows to be simulated in different conditions and regions [16-18]. CFD is also applied in biological and environmental fields; in early 1994, a new FORTRAN code was developed to simulate the airborne particles [19] and in later decades, many research studies were done, based on this method, for air/environment pollution and emission/ transmission of pathogens. In the last two years, more than 50 published papers have used CFD simulations to study the SARS-CoV-2 transfer in various conditions/spaces enabling researchers to theoretically model various pathways of sneezing-/coughing-/talking-caused respiratory particles and how they dispersed in open/closed spaces to study the virus behavior more effectively [20-22].

In 2020, Peng et al. [23] reviewed researches on pathogens' transmission based on CFD methods (checked by various models/algorithms) and studied the factors that caused them to spread in different environments and the air-flow effects on the spreading.

Later, Saqr et al. [24] studied the reproducibility crisis of the COVID-19 virus by dynamic CFD calculations and used a weighted scoring model to propose a new reproducibility index $\left(0 \leq R_{j}^{C F D} \leq 1\right)$ for the virus simulation that was depended on three reproducibility criteria consisting of 10 elements.

An effort has been made in the present study to summarize the research works for using the CFD approach in the last two years on studying the COVID-19 pandemic from different aspects. CFD applications for different COVID19 problems including airborne virus dispersion, respiratory droplets modeling in sneezing and coughing, ventilation layouts, and facial masks were reviewed. Also, special applications of CFD simulations containing COVID sensors, human respiratory tracts, and the UVC virus inactivation have been summarized. There is not any article to review all these aspects of COVID-19 using CFD modeling during these years. Different useful applications of CFD cases for COVID-19 are summarized in Table 1. The main conclusions of each research are reported in a column of this table. Some of them are very important to understand the limitation of COVID-19 health protocols including the social distancing and using facial mask and ventilation types, etc.

\section{Airborne Virus Dispersion}

The main point to start analyzing the potential role of respiratory aerosols in the distribution of infection is to raise the knowledge about the size distribution of aerosols, the mechanisms of respiratory particles production, and the sites of particles production [50]. The airborne dispersion of respiratory particles and droplets under different indoor conditions and ventilation layouts has been investigated to evaluate individuals' cross-infection in confined environments [51-53].

Before the pandemic of COVID-19, several kinds of research were conducted to investigate the dispersion of respiratory droplets from human beings in different environments, using CFD simulation methods [54-56]. Gupta et al. [55] developed a CFD model to predict the transmission of respiratory droplets of an index traveler in an aircraft cabin. They studied the number of particles inhaled by a traveler because of the exhalation particles from another traveler through regular breathing, 100 coughs, and $30 \mathrm{~min}$ talking over a four-hour flight in the confined cabin. Their measurements show that the number of particles inhaled in the coughing case is higher, thus in case of being infected, the fellow passenger can transmit the high amount of infectious droplets to the index passenger. Next year, Gupta et al. [54] used a CFD model to measure the spatial distribution of respiratory particles under the condition similar to the previous study [55] with an influenza outbreak case. The results indicate that using the N95 respirator masks can dramatically decrease the risk of virus transmission. Zhang et al. [57] used CFD numerical simulation method to analyze the distribution of droplets discharged by cough in a confined conference room. They highlighted that ventilation could speed up the discharging of respiratory droplets, but the cough particles are more likely to be distributed by the airflow. In order to detect contaminants in an environment of a confined room, Zhang et al. [58] developed a CFD model to determine the optimal location for virus sensors to be placed. They found that the best place for a sensor is in the middle of the room ceiling, and it can detect the contaminants more accurately if the sensor was acutely sensitive and if the discharge time was higher.

Since the outbreak of COVID-19, scientists has focused most of their attention on the investigation of respiratory droplets produced by people who are infected by this virus. Bhatia and Santis [25] simulated dispersed droplets which are exhaled by a single breath of an index patient placed inside a $10 \mathrm{~m}^{2}$ cabin area, using the $\mathrm{k}-\omega$ ST turbulence model conducted in ANSYS Fluent to provide an insight into visualizing droplets. The results show that about $75 \%$ of droplets disperse within the cabin for up to $2 \mathrm{~m}$ axially behind the infected person by mixing with the airflow during $20 \mathrm{~s}$. This exposes the passenger sitting behind the index patient to the risk of infection by dispersed droplets. Shao et al. [26] have assessed the risks of transmitting the airborne virus by asymptomatic individuals exhale in a confined ventilated space through CFD simulation. Simulation has been conducted under three practical settings that were indicated in Fig. 1: (1) elevator, (2) small classroom and (3) small 


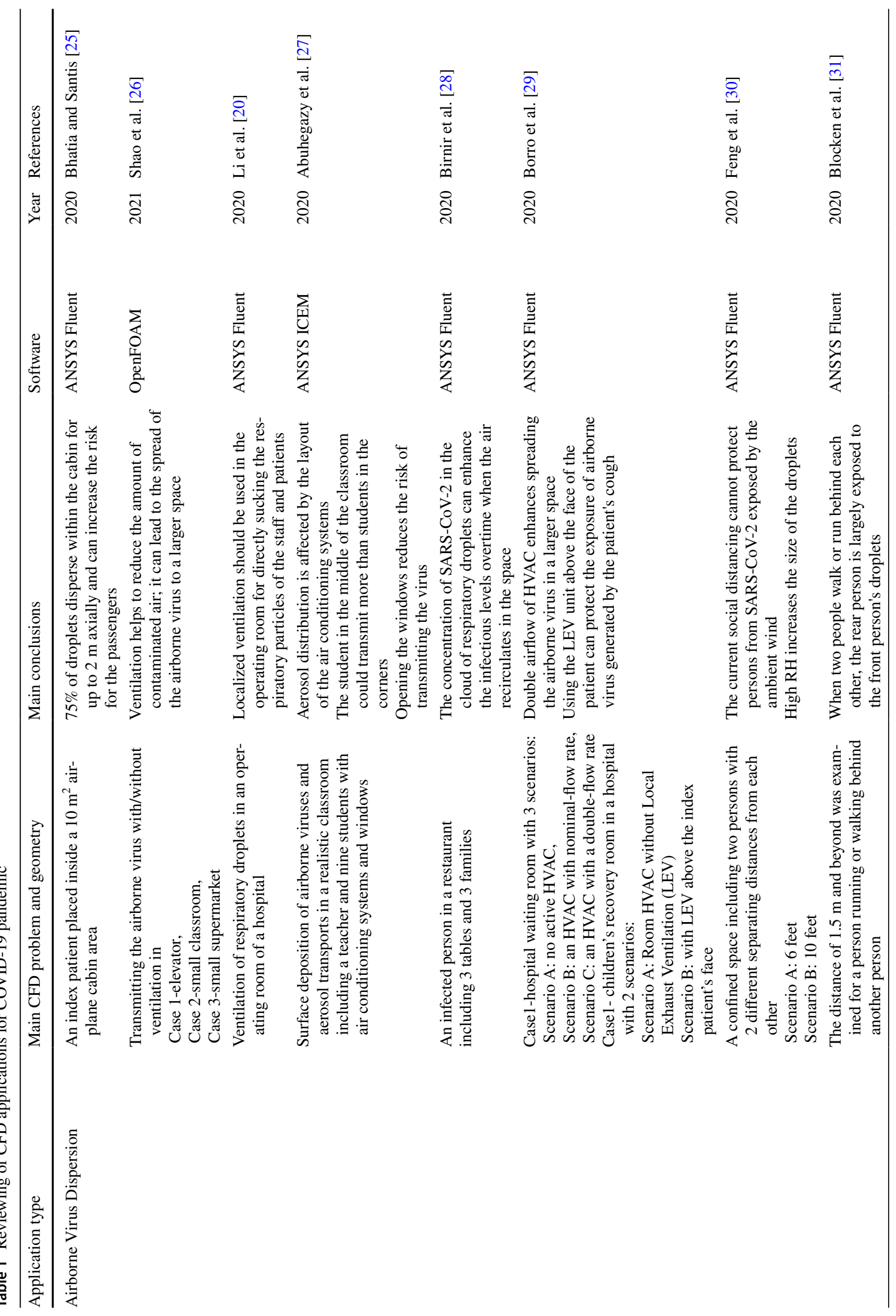




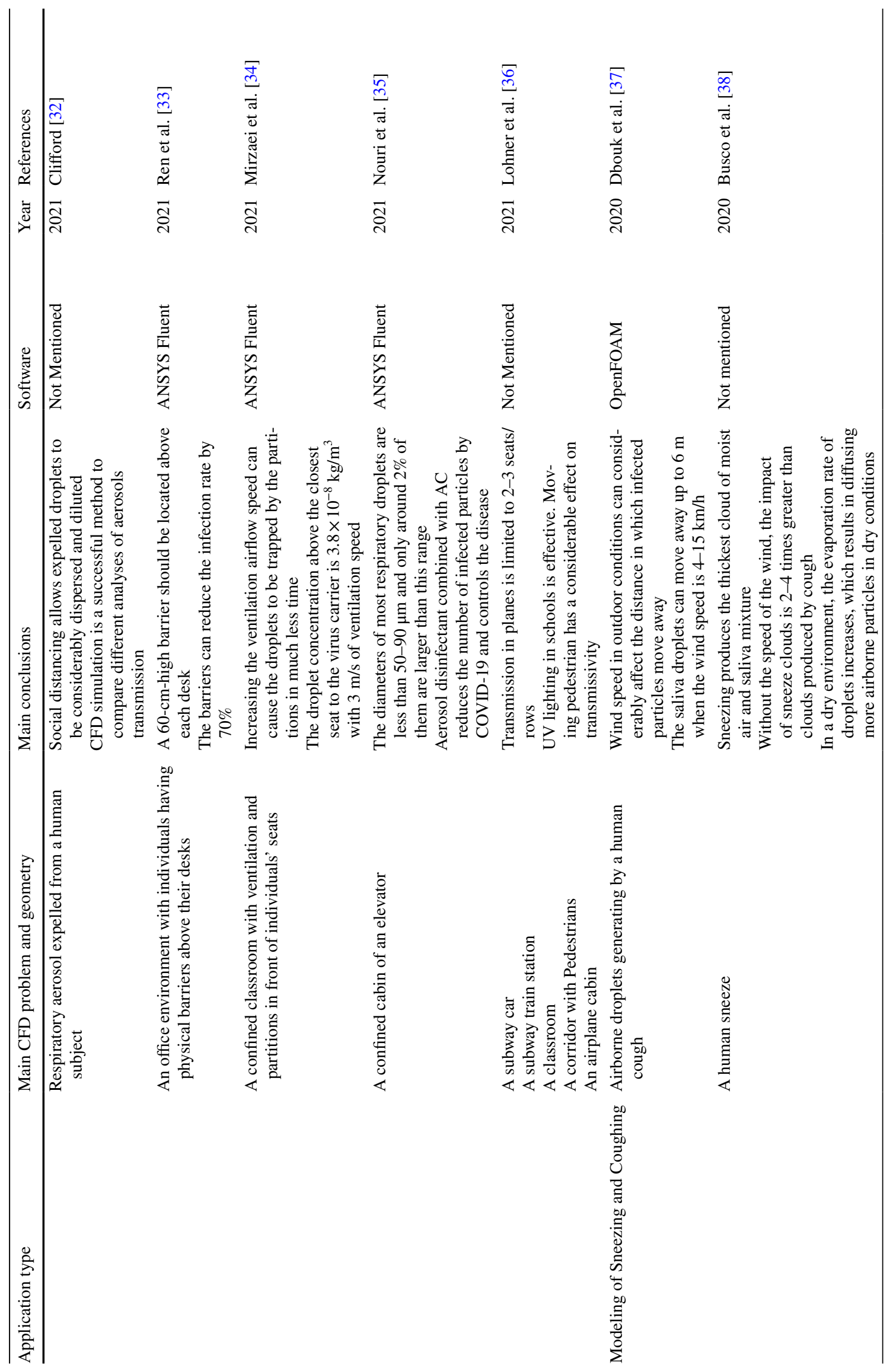




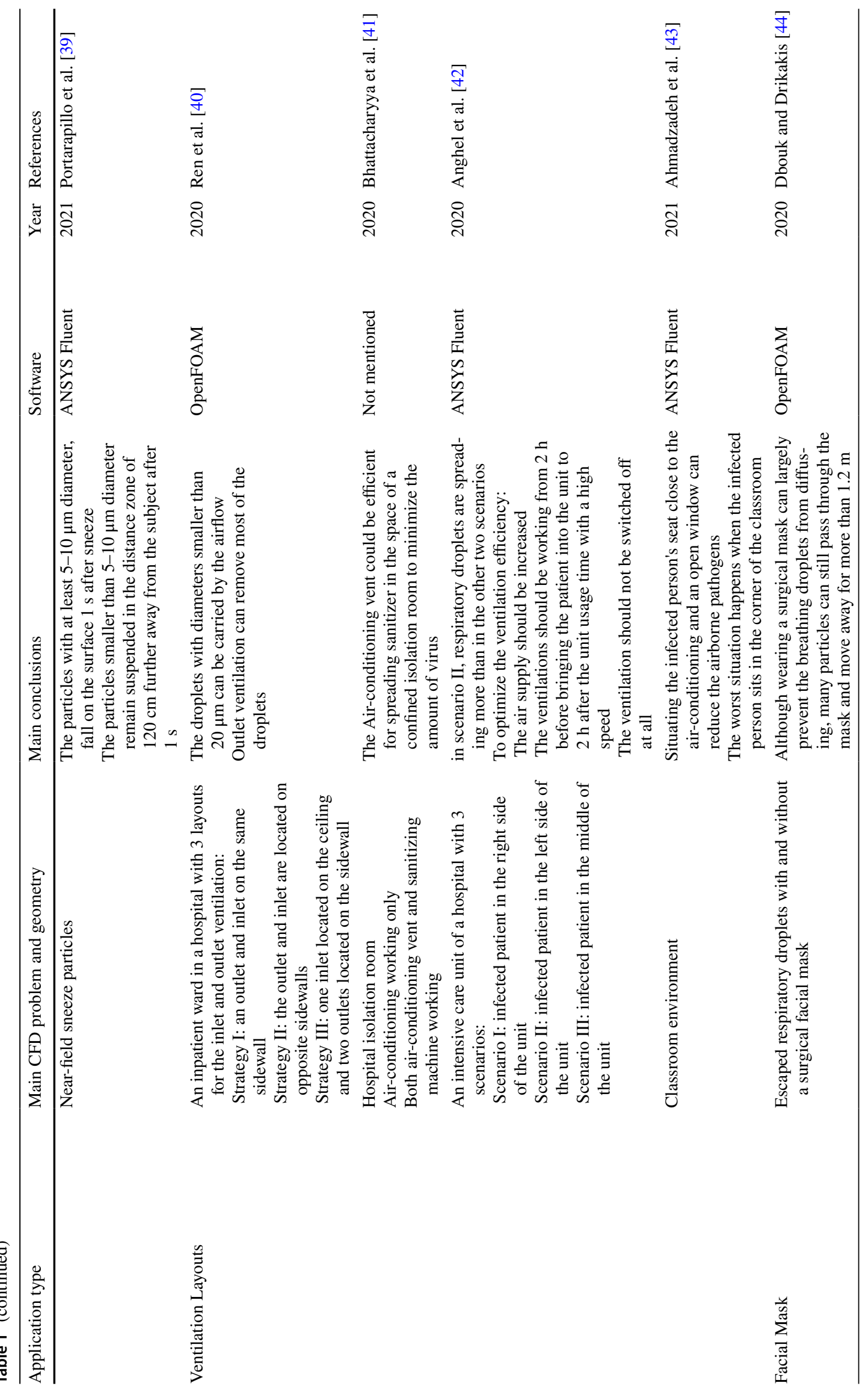




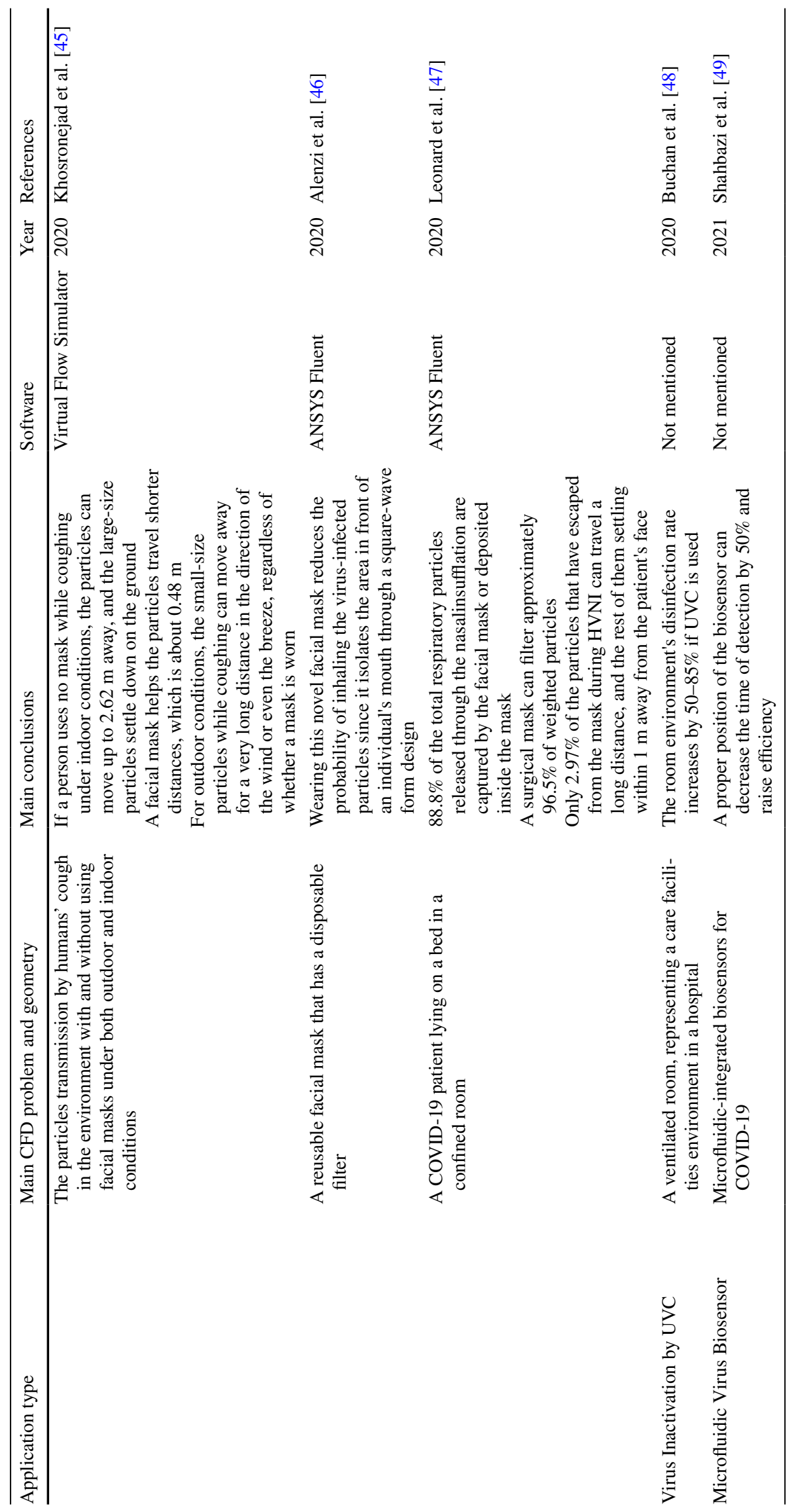


Fig. 1 Particle concentration profiles based on a user-defined function of inhaling risk $\left(I_{\text {risk }}\right)$ of virus-contaminated particles and its average value $\left(\bar{I}_{\text {risk }}\right)$ using the CFD technique at three various closed places with different ventilation scenarios including $\mathbf{a}$ an elevator with three possibilities, $\mathbf{b}$ a classroom with two ventilation situations, and $\mathbf{c}$ a supermarket with two ventilation options (Reprinted with permission from [26] Copyright (2021) Elsevier)
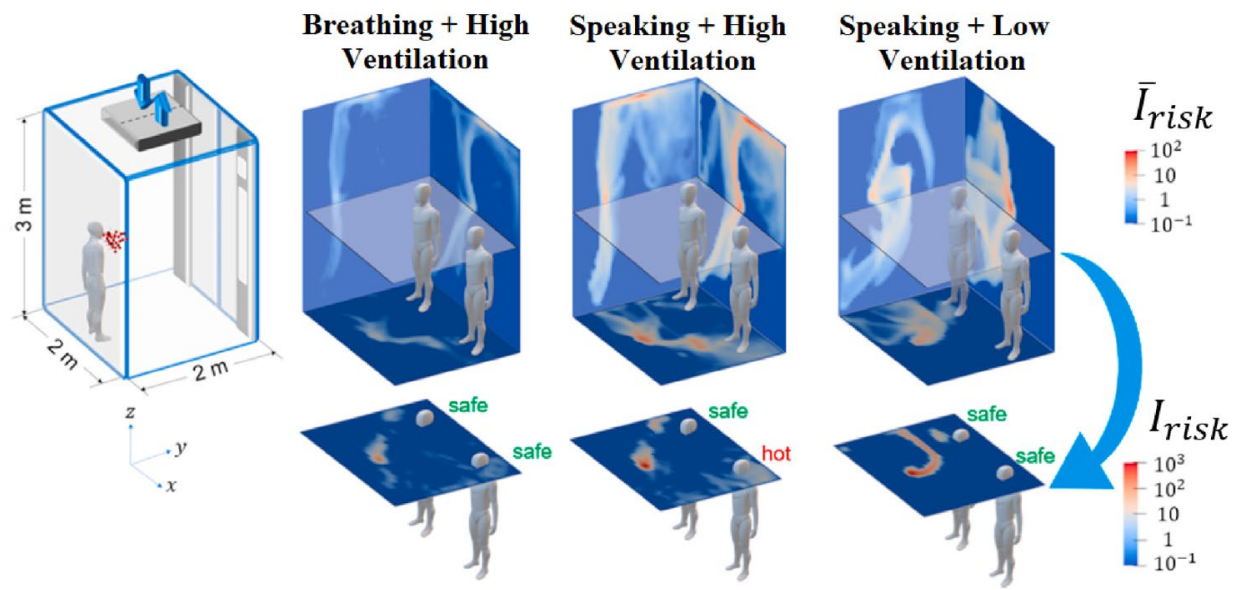

(a) Three different scenarios in an elevator

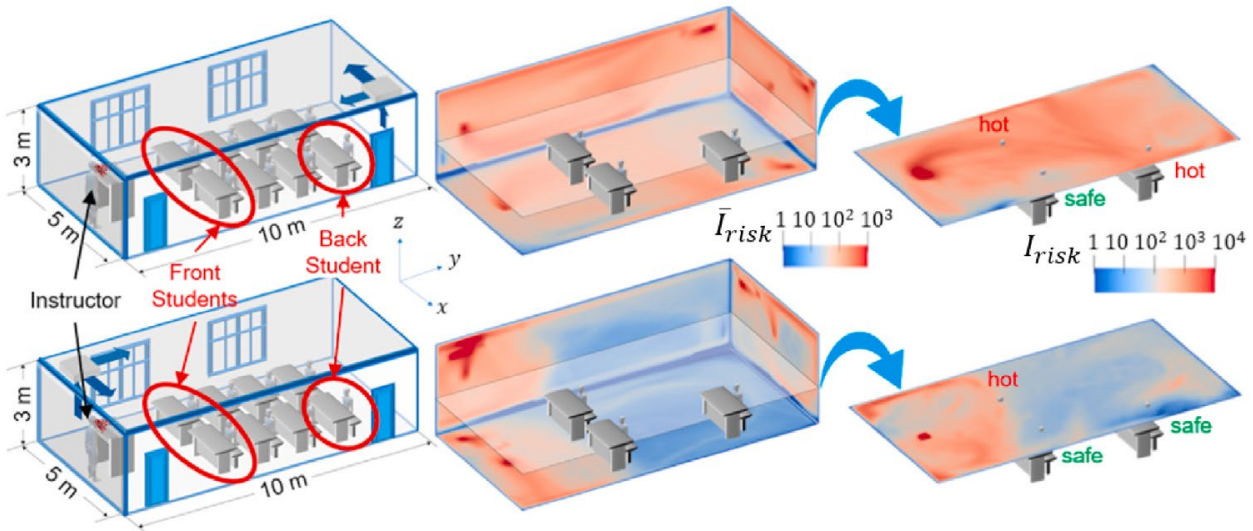

(b) Two different ventilation scenarios in a classroom
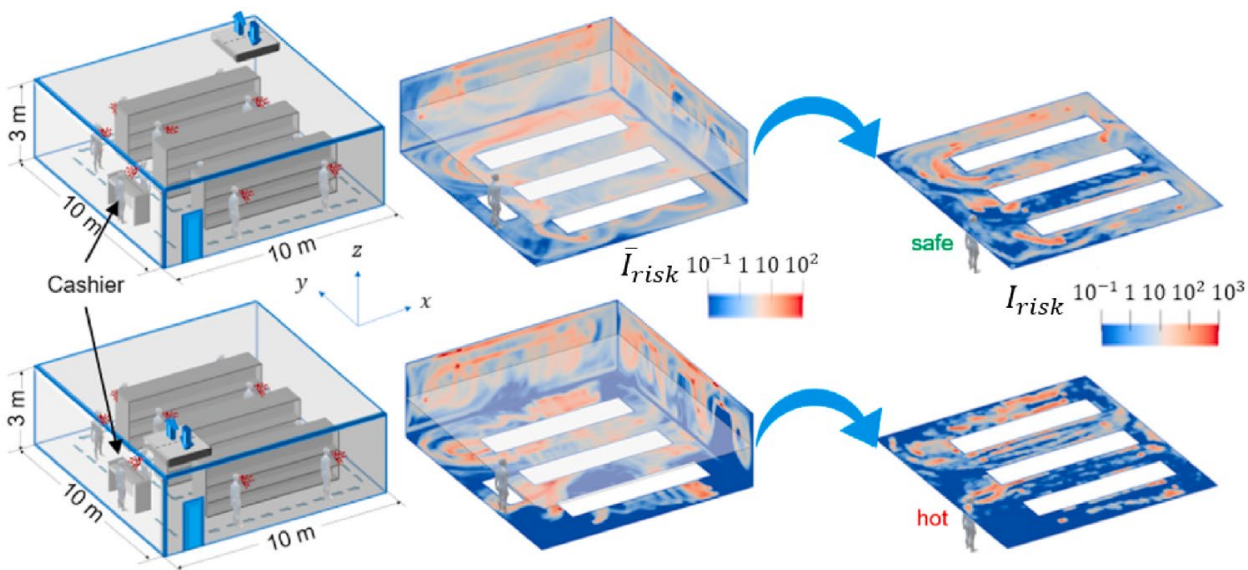

(c) Two different ventilation scenarios in a supermarket supermarket, with different scenarios. The $I_{\text {risk }}$ metric for assessing the risk of COVID-19 transmission is based on the number of particles produced by an individual's exhalation in a specific space during a simulation time and as a result, $I_{\text {risk }}$ is the upper limit of the particles which contains virus and can be contacted by a person. In other words, this number is related to being at the risk of infection [59]. Simulation results show that although ventilation helps to reduce the amount of contaminated air, it can lead to the spread of the airborne virus to a larger space. According to the RNAs samples related to SARS-CoV-2 collected from air vents in hospitals, it can be concluded that ventilation can increase the deposition of contaminated particles on surfaces [6]. These particles which are deposited on the surface can form a very resistant layer of virus that protects viruses from environmental changes and leads to long-lasting contamination 
[60]. These results indicate that ventilation is not sufficient to reduce the number of contaminated particles (both round and faceted). Wearing a mask and determining a proper placement for occupants (in a gym, cabin, etc.) can lessen the risk of infection by the airborne virus.

$\mathrm{Li}$ et al. [20] investigated the influence of ventilation on the respiratory droplets from medical staff and patients in a simulated operating room, using CFD techniques. The CFD model of Zhai et al.'s research [61] was rebuilt to predict the behaviors of the droplets transport in the operating room environment. The equation which governs the air momentum was written in Eq. (1) [62]:

$U_{0}=\frac{\dot{m}}{\rho A_{e}}$

where $\dot{m}$ is the mass flow rate of air $(\mathrm{kg} / \mathrm{s}), \rho$ is the density of inlet air $\left(\mathrm{kg} / \mathrm{m}^{3}\right), A_{\mathrm{e}}$ is inlet effectiveness area $\left(\mathrm{m}^{2}\right)$, and $U_{0}$ is the inlet momentum flux $(\mathrm{m} / \mathrm{s})$. The results reveal that ventilation has a positive effect on reducing the risk of crossinfection between all of the staff and patient, localized ventilation should be used in the operating room that can directly suck the respiratory particles of the individuals.

Abuhegazy et al. [27] used CFD simulation to study the surface deposition of airborne viruses and aerosol transports in a realistic classroom including a teacher and nine students with air conditioning systems and windows. A drag model of Stokes-Cunningham was used to define the particle trajectory and as a result, the motion equation of the particles was written in Eq. (2):

$\frac{d v_{i}}{d t}=\frac{f}{\tau_{p} C_{c}}\left(u_{i}+v_{i}\right)+g_{i}(1-\alpha)+f_{i, \text { Brownian }}+f_{i, l i f t}$

where $f$ is the drag factor [63], $\tau_{p}$ is the reaction time of particles, $u_{i}$ is the flow velocity, and $C c$ is the factor of Cunningham correction [64]. The simulation results indicate that the aerosol distribution in the class environment is not uniform and is significantly affected by the layout of the air conditioning systems. Additionally, the source location of the exhaled particles has a considerable effect on aerosol transport. The student in the middle of the classroom could transmit more of the exhaled particles to others, compared with the students in the corners. Opening the windows is another factor that reduces the number of particles transmitted between occupants.

It has been speculated that the air-conditioning can produce the airflow which blows large droplets of contaminated air [65]. In this regard, Birnir et al. [28] used a distribution model of respiratory aerosols and breathing droplets by Lagrangian turbulent airflow which is exhaled by an infected person in a restaurant in Guangzhou, China [66]. The restaurant including three tables and three families was simulated, where a member of one of the three families was considered infected; air-conditioners' airflow with blowing of $0.25 \mathrm{~m} / \mathrm{s}$ were also set [67]. The results indicate that the concentration of SARS-CoV-2 in the cloud of respiratory droplets can enhance the infectious levels overtime when the air recirculates in the space. It has been shown that in less than $15 \mathrm{~min}$, the concentration of droplets inhaled by each person is what it could be if they were sitting exactly next to the patient and it would be more than four times in one hour.

Borro et al. [29] studied CFD simulation of a patient's cough in 2 different cases in a hospital (Case 1 and Case 2). Case 1 (Fig. 2) was a simulation model in a waiting room, considering three different scenarios; Scenario A: a waiting room with no active HVAC system, Scenario B: a waiting room with an HVAC system that produces nominalflow rate, and Scenario C: a waiting room with an HVAC system which produces double-flow rate. Case 2 (Fig. 3) is a children's recovery room including two hospitalized patients whose body temperatures are $31^{\circ} \mathrm{C}$ (according to Gao et al.'s work [68]). The simulations were performed based on two different scenarios; without (Scenario A) and with (Scenario B) Local Exhaust Ventilation (LEV) system exactly above the index patient's face (in two scenarios there is an HVAC system in the room). The results of the simulation highlight that the HVAC system provides significant space for diffusing the droplets generated by an individual's cough in a closed waiting room (Case 1). Additionally, double airflow of HVAC considerably enhances the motion of turbulent air which results in spreading the contaminated air and airborne virus in a larger space. The simulation results in the recovery room (Case 2) indicate that the HVAC system can easily cause the airflow to be distributed within the space of the room, in the absence of an LEV system, resulting in air contamination dispersion. Using the LEV unit above the face of the patient can protect the exposure of airborne virus generated by patient's cough.

Researches have indicated that SARS-CoV-2 can be spread through exhalation and as a result, the main sources of contamination are sneezing, coughing, or touching the surfaces which are infected by the virus [69]. It has led to defining a social distance to prevent the virus from spreading. However, the policy of social distancing does not consider the impact of relative humidity (RH) and wind on the dispersion of infected droplets from patient's exhalation [70] and neglects the cloud of sneeze droplets which can be thrown for up to 27 feet $(8 \mathrm{~m})$ [71]. Feng et al. [30] simulated a confined space including two virtual humans and set two different distances to separate them $(6$ feet and 10 feet), using a model identical to Zhao et al.'s study [72], by ANSYS Fluent Meshing 19.2. The results indicate that wind can affect the transporting of droplets and this depends on the pattern of the airflow. The current social distancing policy cannot protect individuals from SARS-CoV-2 exposed by the ambient wind. Moreover, 


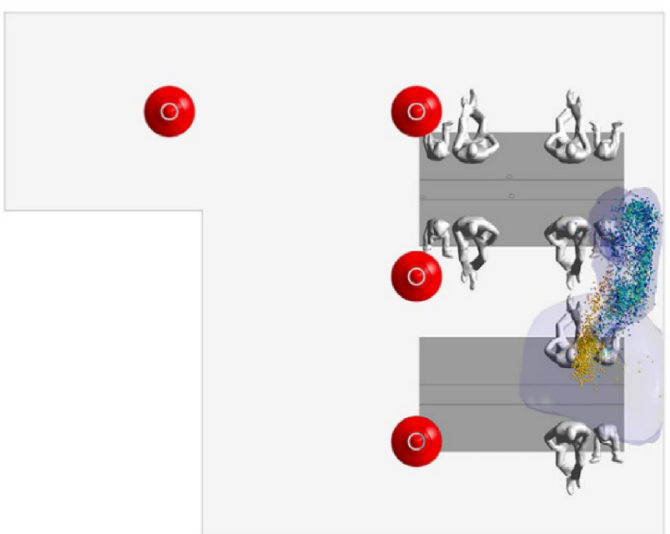

(a) Scenario A, 2D top view

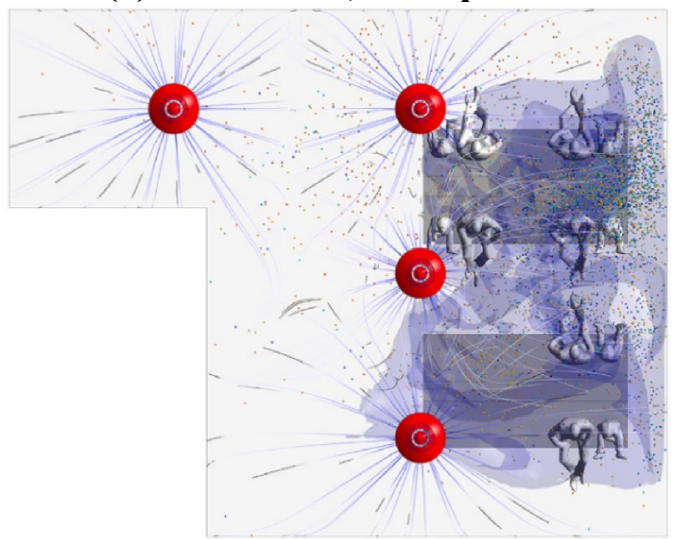

(c) Scenario B, 2D top view

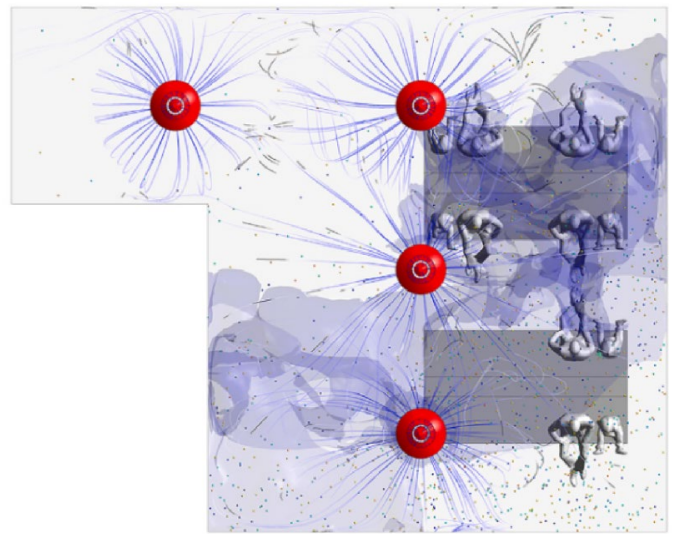

(e) Scenario C, 2D top view

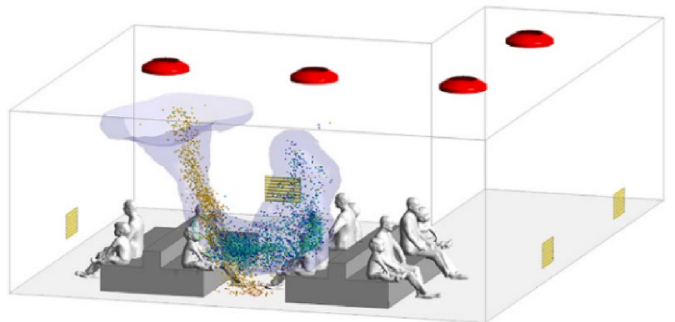

(b) Scenario A, 3D side view

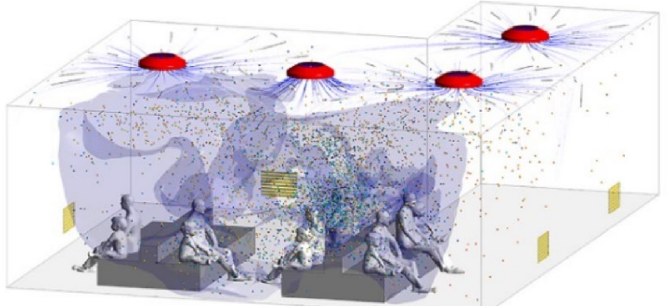

(d) Scenario B, 3D side view

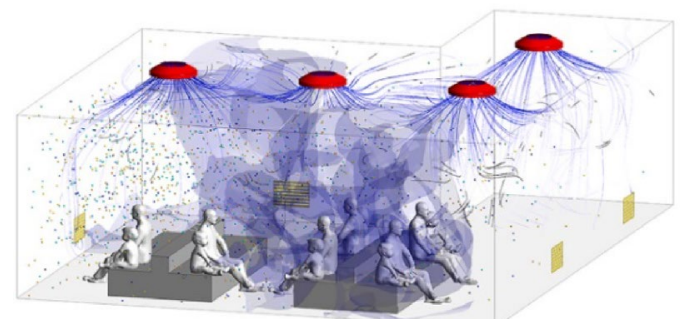

(f) Scenario C, 3D side view

\section{Droplet diameter}

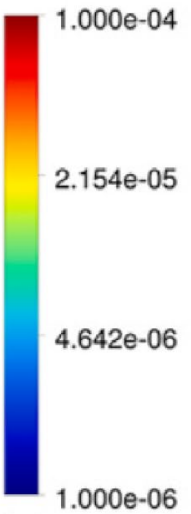

[m]

Mass fraction

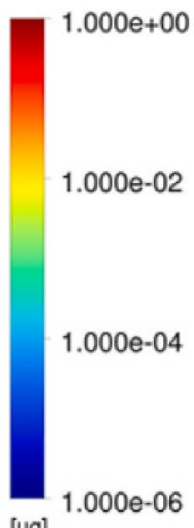

[ $\mu \mathrm{gl}$
Fig. 2 Contour plots of virus mass fraction and distribution of the droplets in different colors based on the droplet diameter for a waiting room of a hospital with 6 men and six children in different forms including 2D top and 3D side views of Scenario A (no HVAC), B (active HVAC with slow flow rate), and $\mathrm{C}$ (active HVAC with fast

High RH increases the condensation impact which helps the size of the droplets to grow while transporting by the airflow. Blocken et al. [31] studied a CFD simulation for investigating the distance in which two individuals could transfer the aerosol droplets to each other. The distance flow rate) at time $=30 \mathrm{~s}$. The air velocity streamlines started from the four inlet diffusers on the top of the room are also illustrated. One person is a virus spreader and located in the middle. (Reprinted with permission from [29] Copyright (2021) Elsevier)

of $1.5 \mathrm{~m}$ and beyond was examined in this case. They performed a simulation of droplets movement generated by exhaling when a person walks or runs nearby another individual, without considering external wind. The results show that when two people walk or run behind each other, 


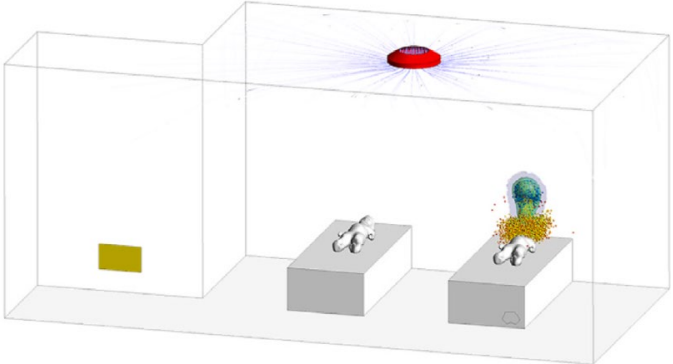

(a) Scenario A, Time $=1 \mathrm{~s}$

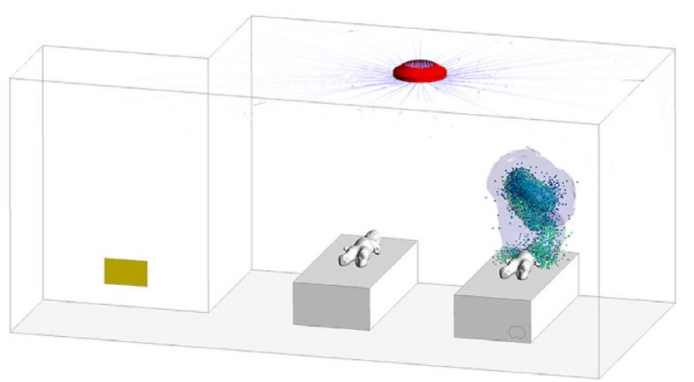

(c) Scenario A, Time = $5 \mathrm{~s}$

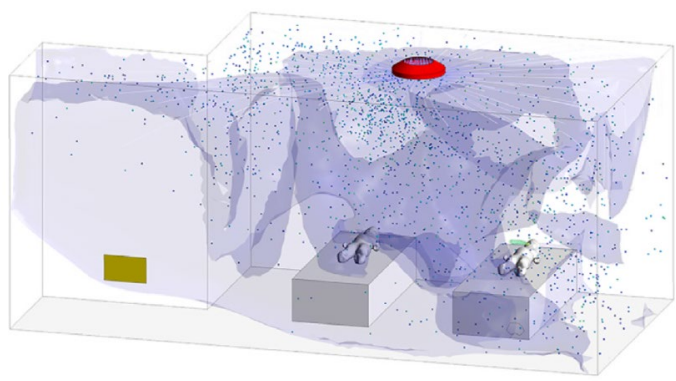

(e) Scenario A, Time $=60 \mathrm{~s}$

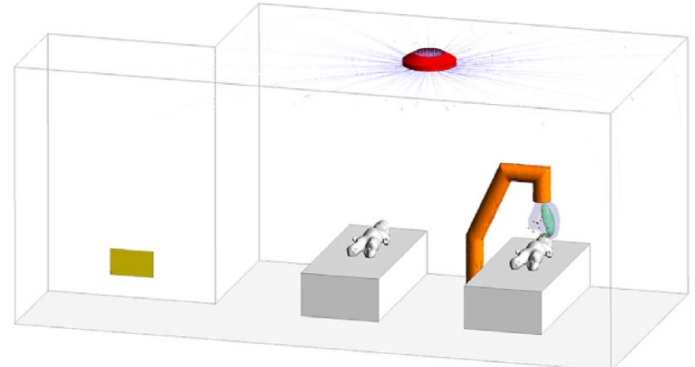

(b) Scenario B, Time $=1 \mathrm{~s}$

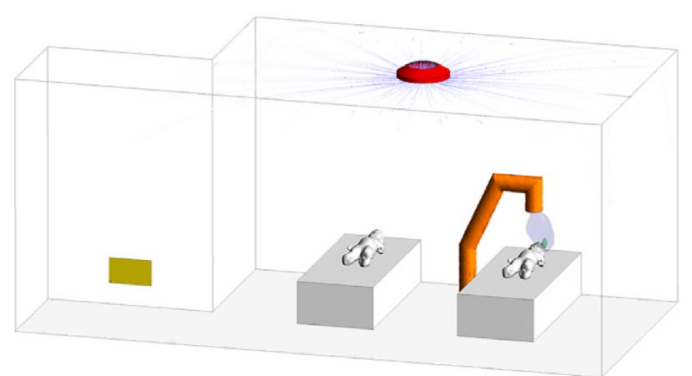

(d) Scenario B, Time $=\mathbf{5} \mathrm{s}$

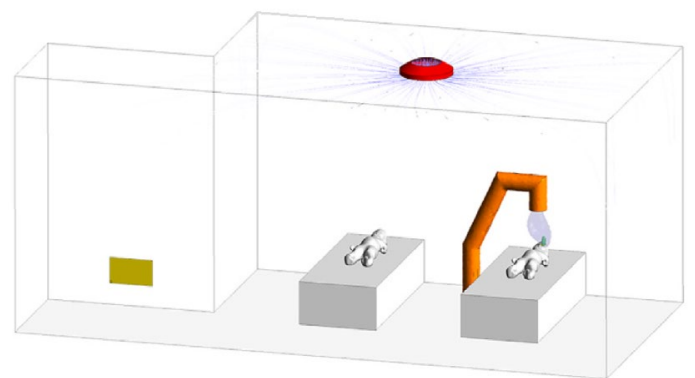

(f) Scenario B, Time $=60 \mathrm{~s}$
Droplet diameter

$1.000 \mathrm{e}-04$
$2.154 \mathrm{e}-05$

$4.642 \mathrm{e}-06$

[m]

Mass

fraction

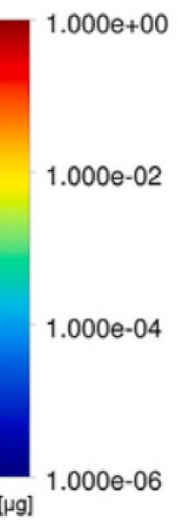

[Hg]

$1.000 \mathrm{e}-06$

m]

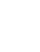


risk of cross-infection and controlling the aerosols spreading in an office environment, using CFD simulation. The results highlight that a $60-\mathrm{cm}$-high barrier should be located above the desks to influentially stop virus dispersion. The height of the workstation's barriers close to outlets is required to be at least $70 \mathrm{~cm}$. With a well-designed ventilation mode, these physical barriers can reduce the infection rate by $70 \%$.

Mirzaie et al. [34] developed a 3D turbulence model to study the airflow and used a Lagrangian analysis to track the respiratory particles in a simulated confined classroom. They investigated the influence of 3 different airflow speeds of ventilation $(3,5,7 \mathrm{~m} / \mathrm{s})$ and the effect of using partitions in front of individuals' seats on the amount of reduced infection and droplets concentration. It is found that although increasing the ventilation airflow speed leads to increasing the particles' velocities, this can cause the droplets to be trapped by the partitions in much less time. Furthermore, without barriers, the individuals are prone to be infected by the virus carrier; the closer to the infected person, the greater the risk of virus transmission. The droplet concentration above the closest seat to the virus carrier was measured to be $3.8 \times 10^{-8} \mathrm{~kg} / \mathrm{m}^{3}$ if the ventilation speed is $3 \mathrm{~m} / \mathrm{s}$.

Lohner et al. [36] summarized the numerical pathogen transmission models in a confined environment via CFD codes, presenting partial differential equations. Subsequently, five different situations were investigated, indicating the following results:

(a) When the pathogen is distributed through a sneeze in a subway car, the large particles (more than $0.1 \mathrm{~mm}$ ) will fall on the floor after $1 \mathrm{~s}$, while the airflow is able to stop the small particles $(0.1 \mathrm{~mm})$ promptly. However, the smaller droplets could travel farther away with the exhaled cloud of the sneezing person. (b) In an airplane cabin, the clouds of sneeze are limited to 2-3 seats/rows. (c) Using three highpowered UV lamps on three different sides of a classroom, the infected particles exposed to UV radiation could be successfully deactivated. (d) The infection rate in a subway train station is approximately $\mathrm{R}=1$, meaning that each infected individual could infect one other pedestrian on average. (e) In a corridor with pedestrians, the large particles would fall on the floor after only $2 \mathrm{~s}$, while the smaller droplets could be noticeably dispersed in the space. This helps the pathogen propagate all over the corridor, leading to extensive virus distribution.

\section{Modeling of Sneezing and Coughing}

A diseased carrier plays an essential role in diffusing the infected droplets by sneezing and coughing. Therefore, scientists have paid growing attention to the mechanism of pathogens spreading. Asymptomatic carriers also potentially and unintentionally spread pathogens by sneezing, because asymptomatic people do sneeze more often than they cough every day [73, 74]. Calculations can predict and analyze the required time for drying the respiratory droplets and are necessary for studying the effect of ambient temperature, particle volume, contact angle, and lifetime duration of pathogens under different conditions [75].

The fluid dynamic of cough and sneeze airflow had been investigated many times by the pandemic of COVID-19 [76, 77]. Researches have shown that sneezing and coughing droplets are the primary sources of virus transmission due to the fact that the particles expelled during these activities are much higher and denser than talking and breathing droplets; their size is also much greater [78, 79]. Comparing men and women in terms of travel distance of their respiratory aerosols, it was shown that during the coughing process, produced droplets from females could move away for 0.16-0.55; this figure is 0.31-0.64 $\mathrm{m}$ for males [77]. Moreover, the maximum sneeze propagation distance was found to be $0.6 \mathrm{~m}$ for individuals, with the airflow velocity of $4.5 \mathrm{~m} / \mathrm{s}$ [76]. It also has been found that that individuals with influenza transmit infectious respiratory particles when coughing, speaking, breathing, and sneezing. Moreover, when people are infected, they generate a greater volume of aerosol droplets during cough than when they are healthy [80].

Chao et al. [59] compared respiratory particles generated through coughing with those of speaking by experimenting on 11 human subjects precisely in the front of their mouth. Their measurements showed that the average velocity of coughing air jet was $11.7 \mathrm{~m} / \mathrm{s}$, compared with $3.1 \mathrm{~m} / \mathrm{s}$ for speaking. Also, the concentration of particles from coughing and speaking turned out to be $2.4-5.2 \mathrm{~cm}^{-3}$ and $0.004-0.223 \mathrm{~cm}^{-3}$, respectively. Gupta et al. [56] used CFD simulation to characterize expelled airflow of cough. The same team [81], next year, studied the flow dynamics of respiratory airflow from breathing and talking by experimenting on 25 healthy human subjects. Comparing the results of the two studies [56, 81], it was found that the peak flow rate during coughing $(6 \mathrm{l} / \mathrm{s}$ for 100 coughs) was higher than that of breathing and talking ( $0.7 \mathrm{l} / \mathrm{s}$ and $1.6 \mathrm{l} / \mathrm{s}$, respectively). However, the total volume of the air generated by breathing and talking (1600 1 and 14001 , respectively) was much higher than coughing (120 1 for 100 coughs) over $2 \mathrm{~h}$, since the process of talking and breathing in nature is continuous, while the process of coughing is impulsive and not permanent.

In order to measure the drag forces (D) between respiratory particles and airflow Lohner and Antil [10.100@ cn] presented an equation Eq. (3):

$\mathrm{D}=\frac{\pi d^{2}}{4} \cdot c_{d} \cdot \frac{1}{2} \rho\left|v-v_{p}\right|\left(v-v_{p}\right)$ 
where $d$ is the diameter of particles, $c_{d}$ is the drag coefficient, $\rho$ is the density of air, $\mathrm{v}$ is the velocity of air, and $v_{p}$ is the velocity of particles.

Dbouk et al. [37] used the "OpenFOAM" code of Computational Fluid Dynamics [82] to investigate the diffusion, transmission, and evaporation of airborne droplets generating by a human cough. They applied an ejection process of respiratory particles to simulate a real cough by humans and utilized a three-dimensional Eulerian-Lagrangian model in order to consider the relative humidity, particle phasechange, droplets evaporation, and interaction between droplets and air. The simulation results illustrate that wind speed in outdoor conditions can considerably affect the distance in which infected particles move away. Without the impact of wind, the droplets will fail to travel more than $1 \mathrm{~m}$ and most of them will fall to the ground. Hence these particles may not endanger the individuals at this distance. However, the saliva droplets are able to move away up to $6 \mathrm{~m}$ when the wind speed is $4-15 \mathrm{~km} / \mathrm{h}$. Thus, it can be concluded that $2 \mathrm{~m}$ social distancing would not be sufficient, depending on different situations.

Busco et al. [38] proposed a CFD approach and experimental-numerical methods to simulate a human sneeze which helps them predict the infected particles and aerosol diffusion. The results indicate that sneezing is the thickest cloud of moist air and saliva mixture. Without the speed of the wind, the impact of sneeze clouds is $2-4$ times greater than clouds produced by cough. Moreover, the number of sneezes during allergy season would raise the risk of pathogen spreading by asymptomatic carriers. Investigating the effect of ambient temperature and humidity, it is found that in a dry environment, the evaporation rate of droplets increases, which results in diffusing more airborne particles in dry conditions. Hence, in the humid and warm environment, the deposition of droplets on the surface hypothetically would rise.

Portarapillo et al. [39] showed that CFD simulation is capable of quantifying the risk indexes for transmitting the infected particles. Using a CFD model of near-field sneeze particles, they build zones of the SARS-CoV-2 effect to detect the safe distance. The results point out that because of gravity, the majority of droplets, the dimension of which is larger than 5-10 $\mu \mathrm{m}$, fall on the surface after $1 \mathrm{~s}$. However, the smaller particles remain suspended, and the distance of the effect zone is measured to be $120 \mathrm{~cm}$ further away from the subject after $1 \mathrm{~s}$.

\section{Ventilation Layouts}

Indoor ventilation and ventilation layouts significantly affect the rate of infection transmission from patients to non-patients [83]. It is very considerable to pay attention to the minimum ventilation rate required for reducing the amount of contamination from airflow [15]. Using numerical CFD simulation, Villafruela et al. [84] examined different ventilation layouts in a room affecting the dispersion of exhaled airflow discharged by human breathing. They indicated that the numerical model is able to accurately predict the distribution pattern of respiratory flows and the characteristics of exhaled contaminants in a confined environment.

Ren et al. [40] investigated three strategies in which different ventilation layouts are provided in a confined space as an inpatient ward with two patients, by modifying a CFD code (OpenFOAM v1906) [85] to simulate the breathing droplets in 3-D turbulent flow (Fig. 4). "Strategy I" includes a ward with an outlet and inlet ventilation on the same sidewall which produces a large air motion in the space. In "Strategy II", the outlet and inlet ventilation are located on the opposite sidewalls which direct the air motion in about half-space. For "Strategy III", the ward includes one inlet ventilation located on the ceiling and two outlet ventilations located on the sidewall. This kind of layout has little effect on the airflow of coughing. To study the diffused flow of particles, an Eulerian-Lagrangian model was used for the simulation which has considered air as a continuum phase and particles as a discrete phase. The model of the particles was considered spherical, with no mass and heat transferring, since the respiratory droplets were small compared to the length of the ward. The density of each particle was $993 \mathrm{~kg} / \mathrm{m}^{3}$ and the measured diameters of them ranged from 3 to $750 \mu \mathrm{m}[59$, 86]. Therefore, the droplets were modeled using Eq. (4):

$m_{p} \cdot \frac{d u_{p}}{d t}=F_{D}+F_{B}+F_{G}$

where the $m_{p}$ is the mass of each particle, $u_{p}$ is the velocity of each particle, $F_{B}$ is the buoyancy force, $F_{G}$ is the gravitational force, and the $\mathrm{F}_{\mathrm{D}}$ is the drag force. The drag force can be defined as follows (Eq. 5):

$F_{D}=3 / 4 \frac{\rho}{\rho_{p}} \frac{m_{p}}{d_{p}} \cdot C_{D}\left(u-u_{p}\right)\left|u-u_{p}\right|$

where $d_{p}$ is the diameter of each particle and $C_{D}$ is defined in Eq. (6):

$\mathrm{C}_{\mathrm{D}}=\left\{\begin{array}{cc}\frac{24}{R e_{p}}\left(1+\frac{\frac{1}{6} R e_{p}^{2}}{3}\right) ; \quad R e_{p}<1000 \\ 0.424 ; \quad R e_{p} \geq 1000\end{array}\right\}$

The term $\mathrm{F}_{\mathrm{B}}+\mathrm{F}_{\mathrm{G}}$ can be calculated by Eq. (7) where the $\mathrm{g}$ value (gravitational acceleration) is $9.81 \mathrm{~m} / \mathrm{s}^{-2}$. 


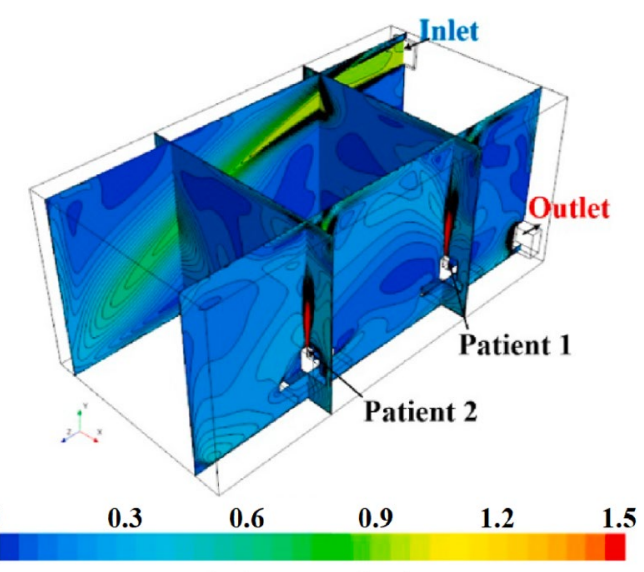

Velocity Magnitude $(\mathrm{m} / \mathrm{s})$

(a) Velocitv contour in ventilation strategy I
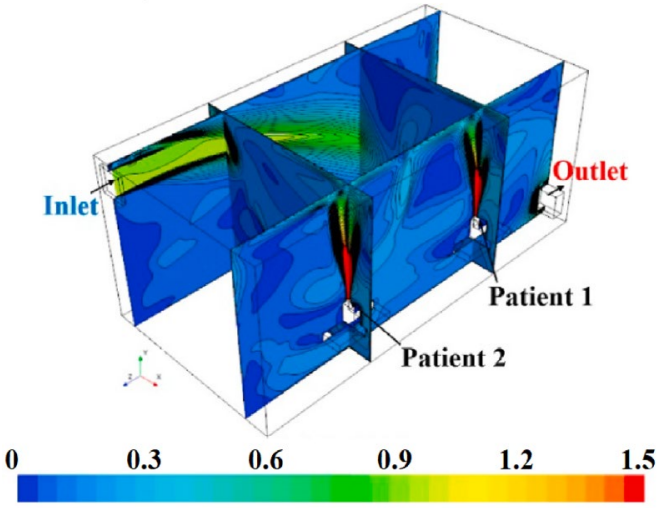

Velocity Magnitude ( $\mathrm{m} / \mathrm{s})$

(c) Velocitv contour in ventilation strategv II

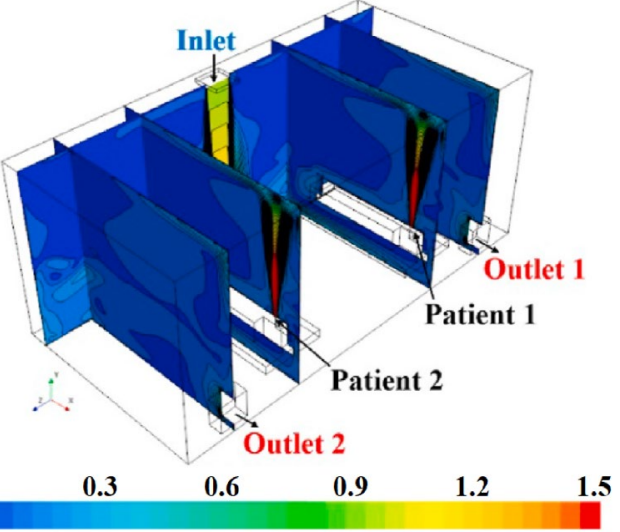

Velocity Magnitude $(\mathrm{m} / \mathrm{s})$

(e) Velocity contour in ventilation strategy III

Fig. 4 Contour plots of 3-D turbulent flow of three ventilation layouts strategies I, II, and III on several cross-planes. a Velocity and b temperature profiles for strategy I, $\mathbf{c}$ velocity and $\mathbf{d}$ temperature profiles

$F_{B}+F_{G}=\frac{\left(\rho_{p}-\rho\right) \pi d_{p}^{3}}{6} g$

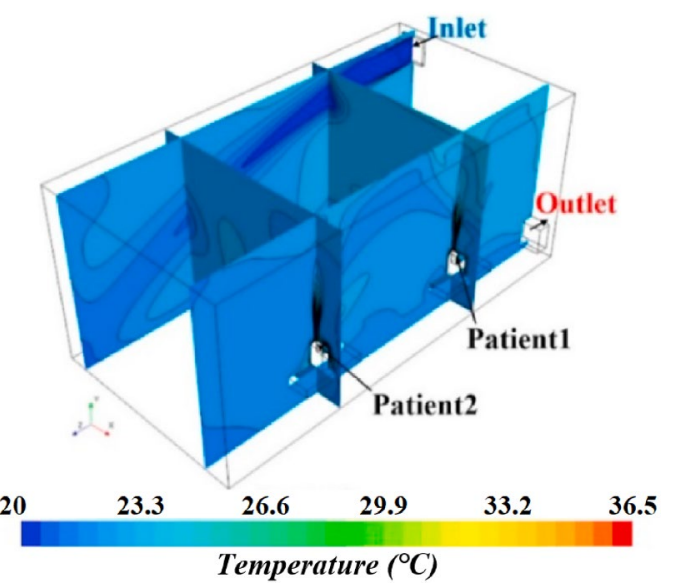

(b) Temperature contour in ventilation strategy I
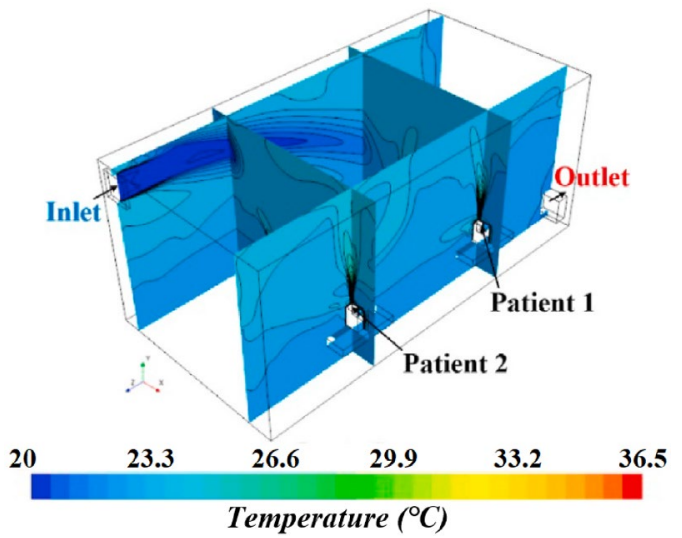

(d) Temperature contour in ventilation strategy II

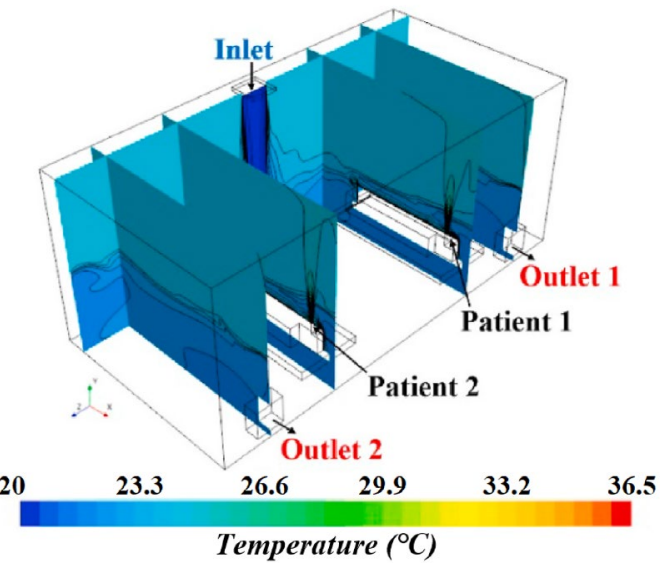

(f) Temperature contour in ventilation strategy III

for strategy II, and e velocity and $\mathbf{f}$ temperature profiles for strategy III, respectively (Reprinted with permission from [40] Copyright (2021) Elsevier)

The results highlight that the droplets with diameters smaller than $20 \mu \mathrm{m}$ can be carried by the main flow and as a result outlet ventilation can remove most of them. The removal percentage of these particles in "Strategy II", is 
Fig. 5. 2D profile of turbulent kinetic energy $\left(\mathrm{m}^{2} / \mathrm{s}^{2}\right)$ for different scenarios: a air-conditioning alone, $\mathbf{b}$ combination of sanitizing machine and air-conditioning. (Reprinted with permission from [41] Copyright (2020)

Elsevier)

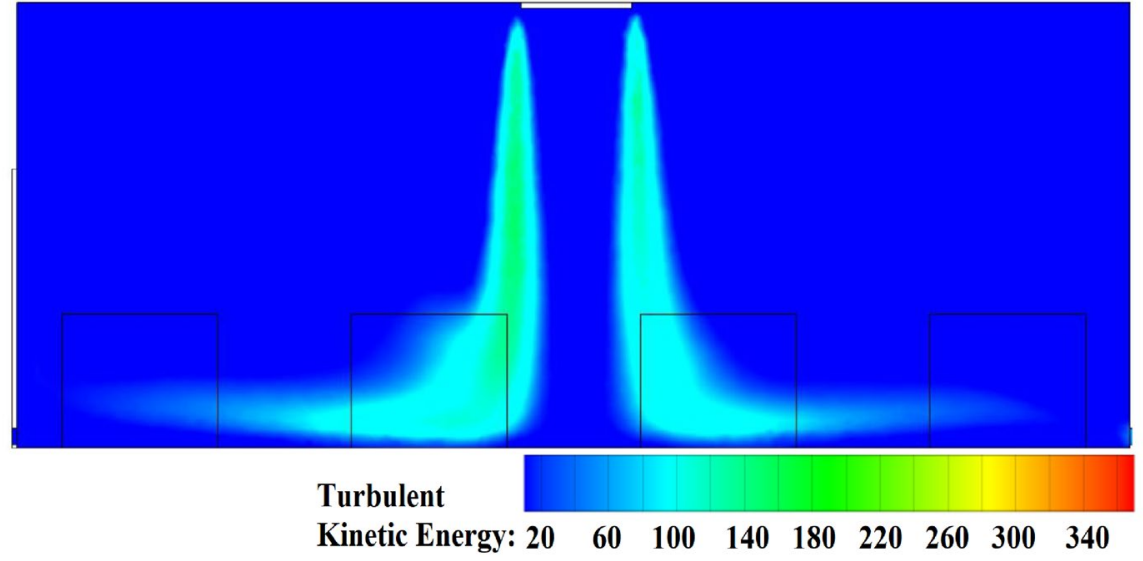

(a) Front view of four hospital beds (four squares) when the air-conditioning system is working alone.

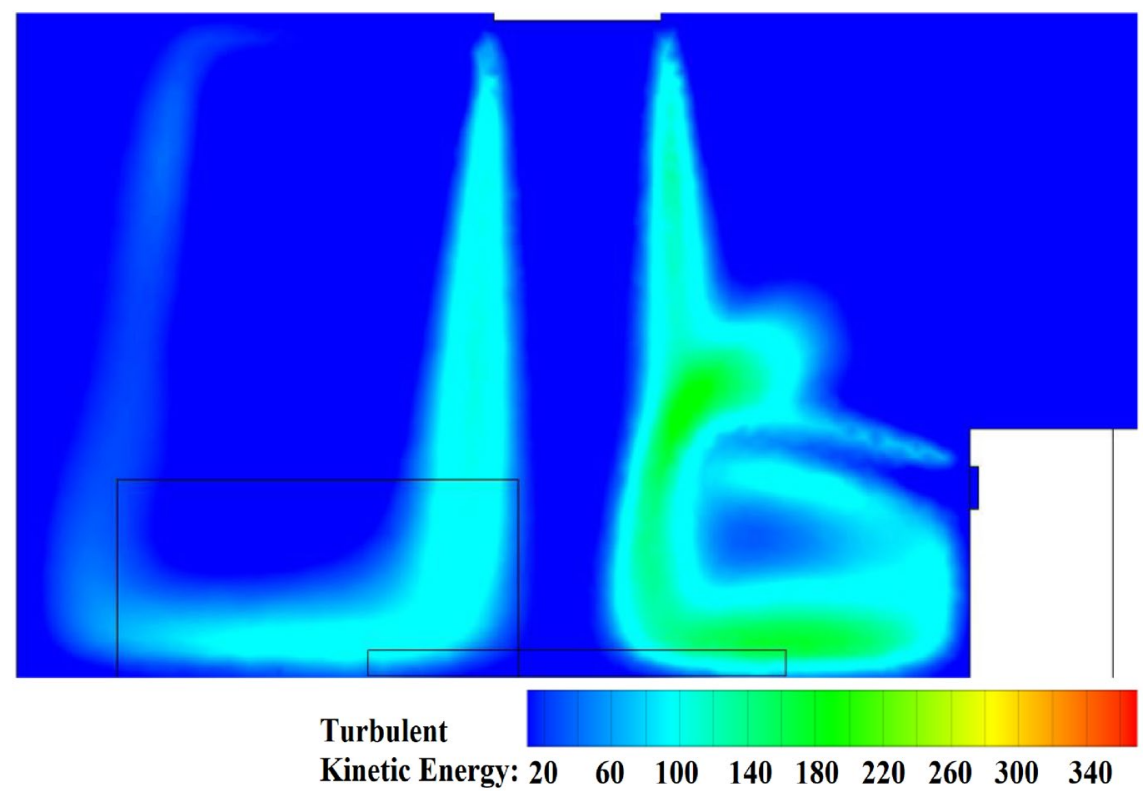

(b) Side view of four hospital beds (that cover each other and only one headmost bed can be seen as a rectangle) when the air-conditioning system and sanitizing machine are working simultaneously.

86.1-88.7, in "Strategy II", is $83.4-85.4$ and in "Strategy III" is 64.3-67.3. Thus, "Strategy I" can remove the smaller particles more efficiently. For larger particles, the breathing droplets cannot move for a long time along with the main flow and fall onto different surfaces. Ventilation using "Strategy III" can remove $18.1 \%$ of larger particles which is the most efficient strategy for removing the larger ones and ventilation with "Strategy III" does not affect removing them. Bhattacharyya et al. [41] studied the effect of conditioned air generated from air-conditioning (AC) vent in order to combine with aerosol sanitizer to degrade COVID-19 virus in a hospital isolation room, using the SST $k-\varepsilon$ model of CFD technique. Figure 5 illustrates the contour plot of the turbulent kinetic energy. Figure 5a shows $\mathrm{AC}$ vent working (without mixing by sanitizer) and Fig. 5b illustrates sanitizing machine and AC vent working at the same time. It is clear that the $\mathrm{AC}$ vent generates a strong turbulence field inside the room which could be efficient for spreading sanitizer in the space of a confined isolation room to minimize the amount of virus.

Anghel et al. [42] used the FEM method of CFD simulation to study the effect of heating, ventilation, and airconditioning (HVAC) in an intensive care unit on the spreading of the infected particles by COVID-19 in the space. They investigated 3 different Scenarios; Scenario I: infected patient in the right side of the unit (patient's 
bed is close to a window, and HVAC is in the middle of the room), Scenario II: infected patient on the left side of the unit (patient's bed is not close to a window, and HVAC is in the central part of the room), Scenario III: infected patient in the middle of the unit (patient's bed is close to the window and inlet grid is exactly above the patient). The results underline that in scenario II, it can be observed that the respiratory droplets are spreading more than in the other two scenarios. Thus, selecting a proper outlet and inlet ventilation position plays an essential role in controlling the virus dispersion. Furthermore, to control the disease and optimize the ventilation efficiency: (a) the air supply should be increased in order to bring outside air into the room as much as possible, (b) the ventilations should be working from $2 \mathrm{~h}$ before bringing the patient into the unit to $2 \mathrm{~h}$ after the unit usage time with a high speed, and (c) the ventilation should not be switched off at all. Instead, they could be working at a lower speed rate in the absence of people.

Ahmadzadeh et al. [43] investigated the impact of airconditioning on the particles transmission discharged during speaking and coughing in a classroom environment, using the Euler-Lagrange model of CFD simulation to track the transport of droplets and RANS equations to calculate the airflow field. The results show that it is possible to noticeably reduce the airborne pathogens by situating the infected person's seat close to the air-conditioning and an open window. Moreover, regarding the cough results, they mention that the worst situation happens when the infected person sits in the corner of the classroom.

Other models also have been developed to theoretically investigate the effect of ventilation. Sun et al. [87] used the Wells-Riley model $[88,89]$ to analyze the effect of social distance and ventilation rate on the risk of infection by COVID-19 in confined rooms, including train, bus, restaurant, etc. The results indicate that the highest infection risk among the public transportations is related to the public bus since the distribution of air and the rate of fresh air in the environment is lower compared to the other public vehicles and the density of occupancy is higher. The minimum rate of ventilation which is requested for the least infection probability increases over time and a targeted social distancing can considerably reduce this required rate.

\section{Facial Mask}

The new pandemic requires effective solutions which call for experts in different fields $[90,91]$. Due to the difficulty of controlling social distance in some environments, it requires personal equipment to protect individuals, and wearing facial masks plays a vital role in this regard [92].
Dbouk and Drikakis [44] investigated the facial mask's role in limiting the number of transmitted droplets using OpenFOAM with a combination of porous and turbulence model and simulated the escaped respiratory droplets with and without a surgical facial mask. The results demonstrate that although wearing a surgical mask can largely prevent the breathing droplets from diffusing, many particles can still pass through the mask and move away for more than $1.2 \mathrm{~m}$. This could be the reason why doctors and nurses can become infected even when they use a facial mask. Hence, using a suitable mask is essential for them to block more particles from the mouth and reduce the risk of cross-infection.

Khosronejad et al. [45] carried out a CFD simulation to investigate the particles transmission by human cough in the environment with and without using facial masks under both outdoor and indoor conditions. The simulation results illustrate that if a person uses no mask while coughing under indoor conditions, the particles can move up to $2.62 \mathrm{~m}$ away, and the large-size particles settle down on the ground. Additionally, smaller particles tend to remain suspended in the air for a few minutes, which results in being inhaled by individuals or being sucked by ventilation. Thus, a facial mask helps the particles travel shorter distances, which is about $0.48 \mathrm{~m}$ by using a medical facial mask. For outdoor conditions, the small-size particles while coughing can move away for a very long distance in the direction of the wind or even the breeze, after a short time, regardless of whether a mask is worn. This happens since there is an upward movement of saliva particulates, even by using a facial mask, and the breeze can cause them to move forward several meters away.

Alenzi et al. [46] designed a reusable facial mask that has a disposable filter and, as a result, can reduce the material requirement by $75 \%$ compared to a traditional facial mask. CFD numerical study was used in this work for simulation of airflow which passes through the mask filters. Wearing this novel facial mask reduces the probability of inhaling the virus-infected particles since it isolates the area in front of an individual's mouth through a square-wave form design. This causes air to enter the facial mask only from the left and right-side filters. This facial mask also has a transparent frame, letting others see the lip so they can lip-read.

Leonard et al. [47] studied the effect of the surgical facial mask on respiratory particles' behavior during highvelocity nasal insufflation (HVNI), using the CFD simulation by ANSYS fluent. A COVID-19 patient lying on a bed was modeled in a confined room with two outlet ventilation on the ceiling and two inlet ventilation on the walls. The simulation results indicate that $88.8 \%$ of the total respiratory particles released through the nasal insufflation are captured by the facial mask or deposited inside the mask. The results also demonstrate that a surgical mask 
can filter approximately $96.5 \%$ of weighted particles. Only $2.97 \%$ of the particles that have escaped from the mask during HVNI can travel a long distance, and the rest of them settling within $1 \mathrm{~m}$ away from the patient's face.

\section{Other Applications}

\subsection{Virus Inactivation by UVC}

Using the UV lamps has been considered for the inactivation of viruses in the absence of vaccines or antiviral drugs over a hundred years [93]. Recent advances in UV lamp technology have led to the generation of short wavelengths UVC. Thus the low-dose UVC light could be suggested to disinfect the air (207-222 nm) [94-96]. Unlike the conventional UVC, which has been used for years to decay the microorganism, but is carcinogenic, recent evidence has indicated that the use of far-UVC is safe for humans $[97,98]$.

Buchan et al. [48] used a high-fidelity fluid dynamics model to investigate the effect of far-UVC radiation on the inactivation of coronavirus and disinfection of a ventilated room, representing a care facilities environment in a hospital including one inlet and one outlet ventilation on the ceiling, the room was occupied by a bed on which a patient lays. The model illustrates that by combining the high ventilation and far-UVC, the required time for $99 \%$ removal in viral count reduces from 24 to $11.5 \mathrm{~min}$. The results also show that the room environment's disinfection rate increases by $50-85 \%$ if UVC is used. According to these results, it is suggested that far-UVC lighting can be applied to reduce the transmission of SARS-COV-2, especially in spaces that do not have adequate ventilation.

\subsection{Microfluidic Virus Biosensor}

Biosensors are pathogen detection systems that are highly sensitive, inexpensive, and easy to use. These systems can be considered as one of the best solutions to reduce death in epidemic diseases [99] and for this purpose, scientists have developed microfluidic integrated biosensors in where a microfluidic channel is connected to electrical chips to analyze the response results. Targeted molecules can enter the microfluidic channel which has a biosensor and have chemical reactions with the elements of biological cognition [100]. To design suitable microfluidic-integrated biosensors for COVID-19, a new numerical model was developed by Shahbazi et al. [49] to solve the equations of full Navier-Stokes based on CVFEM with diffusion, convection, and the reaction of targeted molecules. Figure 6 shows four steps of designing a microfluidic-integrated biosensor. Step 1, shows the study of the virus and its origins, which is vital for step 2 to prepare a perceptual design of integrated biosensor. Step 2, demonstrates a schematic view of the microfluidic channel which is provided with a biosensor. In step 3, the convection, diffusion, buffer fluid flow, and the reaction of targeted molecules are simulated by a numerical model. In the last step, optimization of design is accomplished, based on analysis. Two-dimensional Navier-Stokes equations represented in Eqs. (8)-(10) can be solved for simulating the flow of buffer fluid.

$\rho \frac{\partial u}{\partial t}+\rho\left[\frac{\partial u}{\partial x}+\frac{\partial v}{\partial x}\right]=0$

$\rho \frac{\partial u}{\partial t}+u \frac{\partial u}{\partial x}+v \frac{\partial u}{\partial y}=-\frac{\partial p}{\partial x}+\mu\left(\frac{\partial^{2} u}{\partial \mathrm{x}^{2}}+\frac{\partial^{2} u}{\partial \mathrm{y}^{2}}\right)$

$\rho \frac{\partial v}{\partial t}+u \frac{\partial v}{\partial x}+v \frac{\partial v}{\partial y}=-\frac{\partial p}{\partial y}+\mu\left(\frac{\partial^{2} v}{\partial \mathrm{x}^{2}}+\frac{\partial^{2} v}{\partial \mathrm{y}^{2}}\right)$

where $v$ is the velocity in the $y$-direction and $u$ is the velocity in the $x$-direction, while $\mu$ is the molecular viscosity and $\rho$ is the density. An equation can be generated by Fick's law (Eq. 11) to model the kinetics of biological species (Eq. 12).

$\mathrm{F}=-\mathrm{D} \nabla \mathrm{c}$

$\frac{\partial c}{\partial t}+\vec{U} \cdot \nabla \mathrm{c}=\nabla \cdot(\mathrm{D} \nabla \mathrm{c})+\mathrm{S}$

where $D$ is the coefficient of diffusion, $S$ is a term that is considered zero in this equation and $c$ is the of the targeted molecules' concentration. Using the mechanism of Langmuir-Hinshelwood [101], the kinetics of heterogeneous biosensors can be modeled (Eq. 13).

$\frac{\partial b}{\partial t}=k_{o n} c_{0}\left(b_{\max }-b\right)-k_{\text {off }} b$

where $\mathrm{b}$ is the bound analyte surface concentration [102], $k_{\text {on }}$ is the rate of adsorption, $k_{\text {off }}$ is the dissociation rate of the sensor, $b_{\max }$ is the binding site density on the sensor and $c 0$ is the inlet concentration. The results show that the biosensor position has a considerable impact on efficiency; a proper position can decrease the time of detection by $50 \%$.

\section{Conclusion}

In recent years, the use of CFD simulations has played an essential role in solving complex fluid and predicting turbulent flow behavior in many case studies. In this article, we reviewed different CFD simulations which are exactly 
Fig. 6 Illustration of a 4-step procedure for developing a microfluidic biosensor for detection of COVID-19 virus using the CFD approach. (Reprinted with permission from [49] Copyright (2021) Elsevier)

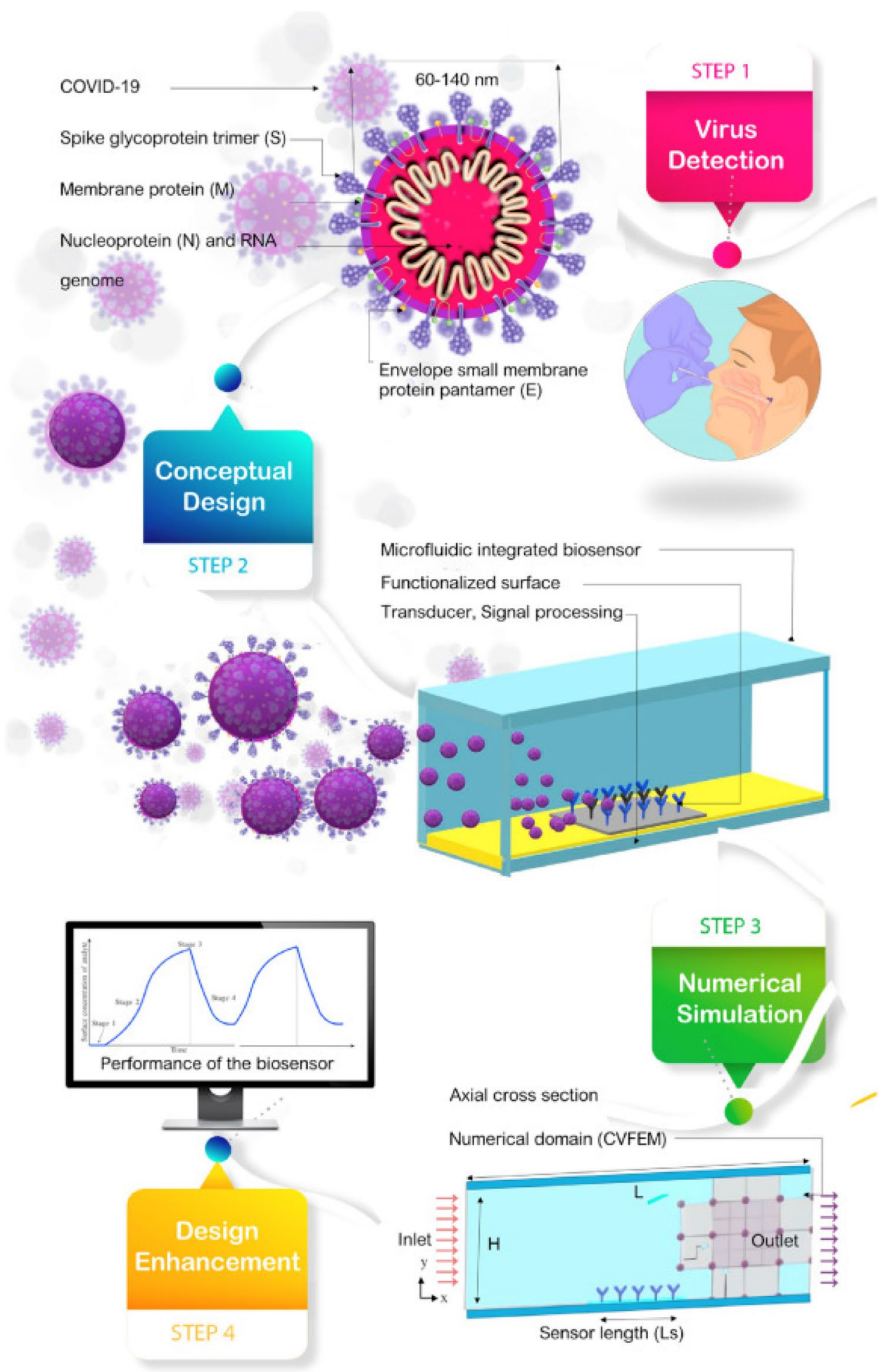

related to the COVID-19 pandemic in recent years (2020 and 2021). These include simulation of airborne virus dispersion, modeling of sneezing and coughing, comparing ventilation layouts, the effect of using/not using a facial mask, modeling of the virus inactivation by UVC radiation, and simulation of microfluidic virus sensor.
The main results that can be found from the application CFD modeling in COVID-19 are summarized as the following:

- The current outdoor social distancing cannot protect individuals from COVID-19 because of the impact of wind; 
the saliva droplets are able to move away up to $6 \mathrm{~m}$ under the influence of wind.

- Although ventilation leads to the spread of the airborne virus to a larger space, it still helps to reduce the amount of infected air by sucking the respiratory particles produced by disease carriers.

- Aerosol disinfectant combined with air-conditioning (AC) decreases the number of infected particles due to the fact that AC can help disinfectant to spread in a larger space.

- The cloud produced by sneezing can be more concentrated than the coughing cloud.

- To optimize ventilation efficiency, we should raise the rate of air change and the use of outdoor air filters. Air recirculation also should be reduced.

- A facial mask helps the particles travel shorter distances and captures $88.8 \%$ of the total respiratory particles and $96.5 \%$ of weighted particles.

- By using UVC light, the room's disinfection rate increases by $50-85 \%$.

- To decrease the detection time of the virus biosensor a proper position is required.

\section{Declarations}

Conflict of interest The authors did not have any conflict of interests to be declared.

\section{References}

1. Setti L et al (2020) Airborne transmission route of COVID19: why 2 meters/ 6 feet of inter-personal distance could not be enough. Int J Environ Res Public Health 17(8):2932

2. Anderson RM, Heesterbeek H, Klinkenberg D, Hollingsworth TD (2020) How will country-based mitigation measures influence the course of the COVID-19 epidemic? Lancet 395(10228):931-934

3. IRIS Home. [Online]. https://apps.who.int/iris/. Accessed $28 \mathrm{Apr}$ 2021

4. Gralton J, Tovey E, McLaws ML, Rawlinson WD (2011) The role of particle size in aerosolised pathogen transmission: a review. $\mathrm{J}$ Infect 62(1):1-13

5. Asadi S, Bouvier N, Wexler AS, Ristenpart WD (2020) The coronavirus pandemic and aerosols: does COVID-19 transmit via expiratory particles? Aerosol Sci Technol 54(6):635-638

6. Liu Y et al (2020) Aerodynamic analysis of SARS-CoV-2 in two Wuhan hospitals. Nature 582(7813):557-560

7. van Doremalen $\mathrm{N}$ et al (2020) Aerosol and surface stability of SARS-CoV-2 as compared with SARS-CoV-1. N Engl J Med 382(16):1564-1567

8. Johnson GR, Morawska L (2009) The mechanism of breath aerosol formation. J Aerosol Med Pulm Drug Deliv 22(3):229-237

9. Zou L et al (2020) SARS-CoV-2 viral load in upper respiratory specimens of infected patients. N Engl J Med 382(12):1177-1179
10. Li Y, Huang X, Yu ITS, Wong TW, Qian H (2005) Role of air distribution in SARS transmission during the largest nosocomial outbreak in Hong Kong. Indoor Air 15(2):83-95

11. Li Y et al (2007) Role of ventilation in airborne transmission of infectious agents in the built environment: a multidisciplinary systematic review. Indoor Air 17(1):2-18

12. Tang JW, Li Y, Eames I, Chan PKS, Ridgway GL (2006) Factors involved in the aerosol transmission of infection and control of ventilation in healthcare premises. J Hosp Infect 64(2):100-114

13. Beggs CB, Kerr KG, Noakes CJ, Hathway EA, Sleigh PA (2008) The ventilation of multiple-bed hospital wards: review and analysis. Am J Infect Control 36(4):250-259

14. Gu D, Zheng Z, Zhao P, Xie L, Xu Z, Lu X (2020) High-efficiency simulation framework to analyze the impact of exhaust air from covid-19 temporary hospitals and its typical applications. Appl Sci 10(11):3949

15. Jiang Y, Zhao B, Li X, Yang X, Zhang Z, Zhang Y (2009) Investigating a safe ventilation rate for the prevention of indoor SARS transmission: an attempt based on a simulation approach. Build Simul 2(4):281-289

16. Lomax H, Pulliam TH, Zingg DW (2001) Finite-difference approximations. In: Fundamentals of computational fluid dynamics. Springer, Berlin, pp 19-47. https://doi.org/10.1007/ 978-3-662-04654-8_3

17. Roache PJ (1997) Quantification of uncertainty in computational fluid dynamics. Annu Rev Fluid Mech 29(1):123-160

18. Chu CK (1979) Computational fluid dynamics. In: Parter SV (ed) Numerical methods for partial differential equations. Academic Press (Elsevier), Amsterdam, pp 149-175. https://doi.org/10. 1016/B978-0-12-546050-7.50009-5

19. Ginger LG (1944) The chemistry of the lipids of tubercle bacilli. J Biol Chem 156(2):453-456

20. Li H, Zhong K, Zhai Z (2020) Investigating the influences of ventilation on the fate of particles generated by patient and medical staff in operating room. Build Environ 180(April):1-11

21. Liu H, He S, Shen L, Hong J (2020) Simulation-based study on the COVID-19 airborne transmission in a restaurant. medRxiv

22. Cui F et al (2021) Transport and fate of virus-laden particles in a supermarket: recommendations for risk reduction of COVID-19 spreading. J Environ Eng 147(4):04021007

23. Peng S, Chen Q, Liu E (2020) The role of computational fluid dynamics tools on investigation of pathogen transmission: prevention and control. Sci Total Environ 746:142090

24. Saqr KM Amicus Plato, sed magis amica veritas: there is a reproducibility crisis in COVID-19 computational fluid dynamics studies [online]. https://arxiv.org/abs/2101.04874. Accessed 11 Jan 2022

25. Bhatia D, De Santis A (2020) A preliminary numerical investigation of airborne droplet dispersion in aircraft cabins. Open J Fluid Dyn 10(03):198-207

26. Shao $\mathrm{S}$ et al (2021) Risk assessment of airborne transmission of COVID-19 by asymptomatic individuals under different practical settings. J Aerosol Sci 151(August 2020):105661

27. Abuhegazy M, Talaat K, Anderoglu O, Poroseva SV, Talaat K (2020) Numerical investigation of aerosol transport in a classroom with relevance to COVID-19. Phys Fluids 32(10):103311

28. Birnir B, Angheluta L (2020) The build-up of droplet/aerosols carrying the SARS-CoV-2 Coronavirus, in confined spaces. medRxiv, pp 2-13

29. Borro L, Mazzei L, Raponi M, Piscitelli P, Miani A, Secinaro A (2021) The role of air conditioning in the diffusion of SarsCoV-2 in indoor environments: a first computational fluid dynamic model, based on investigations performed at the Vatican State Children's hospital. Environ Res 193(August 2020):110343 
30. Feng Y, Marchal T, Sperry T, Yi H (2020) Influence of wind and relative humidity on the social distancing effectiveness to prevent COVID-19 airborne transmission: a numerical study. J Aerosol Sci 147(May):105585

31. Blocken B, Malizia F, van Druenen T, Marchal T Towards aerodynamically equivalent COVID19 $1.5 \mathrm{~m}$ social distancing for walking and running [online]. http://www.urbanphysics.net/ COVID19_Aero_Paper.pdf. Accessed 11 Jan 2022

32. Ho CK (2021) Modeling airborne pathogen transport and transmission risks of SARS-CoV-2. Appl Math Model 95:297-319

33. Ren C et al (2021) Mitigating COVID-19 infection disease transmission in indoor environment using physical barriers. Sustain Cities Soc 74(June): 103175

34. Mirzaie M, Lakzian E, Khan A, Warkiani ME, Mahian O, Ahmadi G (2021) COVID-19 spread in a classroom equipped with partition: a CFD approach. J Hazard Mater 420(June):126587

35. Nouri Z, Norouzi N, Norouzi N, Ataei E, Azizi S (2021) Virologic microparticle fluid mechanics simulation: COVID-19 transmission inside an elevator space. Int J Comput Mater Sci Eng 10:2150007

36. Löhner R, Antil H, Srinivasan A, Idelsohn S, Oñate E (2021) High-fidelity simulation of pathogen propagation, transmission and mitigation in the built environment. Arch Comput Methods Eng 28(6):4237-4262

37. Dbouk T, Drikakis D (2020) On coughing and airborne droplet transmission to humans. Phys Fluids 32(5):053310

38. Busco G, Yang SR, Seo J, Hassan YA (2020) Sneezing and asymptomatic virus transmission. Phys Fluids 32(7):073309

39. Portarapillo M, Di Benedetto A (2021) Methodology for risk assessment of COVID-19 pandemic propagation. J Loss Prev Process Ind 72(June): 104584

40. Ren J, Wang Y, Liu Q, Liu Y (2021) Numerical study of three ventilation strategies in a prefabricated COVID-19 inpatient ward. Build Environ 188(November 2020):107467

41. Science N, Phenomena C, Bhattacharyya S, Dey K, Ranjan A, Biswas R (2020) A novel CFD analysis to minimize the spread of COVID-19 virus in hospital isolation room. Chaos Solitons Fractals Interdiscip 139:110294

42. Anghel L, St C, Sasc R, Verdes M (2020) Impact of HVACsystems on the dispersion of infectious aerosols in a cardiac intensive care unit. IJERPH 17(18):6582

43. Ahmadzadeh M, Farokhi E, Shams M (2021) Investigating the effect of air conditioning on the distribution and transmission of COVID-19 virus particles. J Clean Prod 316(June): 128147

44. Dbouk T, Drikakis D (2020) On respiratory droplets and face masks. Phys Fluids 32(6):063303

45. Khosronejad A et al (2020) Fluid dynamics simulations show that facial masks can suppress the spread of COVID-19 in indoor environments. AIP Adv 10(12):125109

46. Alenezi H, Cam ME, Edirisinghe M (2021) A novel reusable anti-COVID-19 transparent face respirator with optimized airflow. Bio-Des Manuf 4(1):1-9

47. Leonard S et al (2020) Reducing aerosol dispersion by high flow therapy in COVID-19: high resolution computational fluid dynamics simulations of particle behavior during high velocity nasal insufflation with a simple surgical mask. J Am Coll Emerg Physicians Open 1(4):578-591

48. Buchan AG, Yang L, Atkinson KD (2020) Predicting airborne coronavirus inactivation by far-UVC in populated rooms using a high-fidelity coupled radiation-CFD model. Sci Rep 10(1):1-7

49. Shahbazi F, Jabbari M, Esfahani MN, Keshmiri A (2021) A computational simulation platform for designing real-time monitoring systems with application to COVID-19. Biosens Bioelectron 171(June 2020):112716

50. Johnson GR et al (2011) Modality of human expired aerosol size distributions. J Aerosol Sci 42:839-851
51. Ai ZT, Melikov AK (2018) Airborne spread of expiratory droplet nuclei between the occupants of indoor environments: a review. Indoor Air 28(4):500-524

52. Mui KW, Wong LT, Wu CL, Lai ACK (2009) Numerical modeling of exhaled droplet nuclei dispersion and mixing in indoor environments. J Hazard Mater 167(1-3):736-744

53. Chen C, Zhao B (2010) Some questions on dispersion of human exhaled droplets in ventilation room: answers from numerical investigation. Indoor Air 20(2):95-111

54. Gupta JK, Lin CH, Chen Q (2012) Risk assessment of airborne infectious diseases in aircraft cabins. Indoor Air 22(5):388-395

55. Gupta JK, Lin C-H, Chen Q (2011) Inhalation of expiratory droplets in aircraft cabins. Indoor Air 21(4):341-350

56. Gupta JK, Lin C, Chen Q (2009) Flow dynamics and characterization of a cough. Indoor Air 19(6):517-525

57. Zhang Y, Feng G, Kang Z, Bi Y, Cai Y (2017) Numerical simulation of coughed droplets in conference room. Procedia Eng 205:302-308

58. Zhang T, Chen QY, Lin CH (2007) Optimal sensor placement for airborne contaminant detection in an aircraft cabin. HVAC R Res 13(5):683-696

59. Chao CYH, Wan MP, Morawska L, Johnson GR, Ristovski ZD, Hargreaves M (2009) Characterization of expiration air jets and droplet size distributions immediately at the mouth opening. J Aerosol Sci 40:122-133

60. Van Doremalen N, Bushmaker T, Morris DH, Holbrook MG, Gamble A, Williamson BN et al (2020) Aerosol and surface stability of SARS-CoV-2 as compared with SARS-CoV-1. N Engl J Med 382:1564-1567

61. Zhai ZJ, Osborne AL (2013) Simulation-based feasibility study of improved air conditioning systems for hospital operating room. Front Archit Res 2(4):468-475

62. Chen Q, Suter P, Moser A (1991) Influence of air supply parameters on indoor air diffusion. Build Environ 26(4):417-431

63. Morsi SA, Alexander AJ (1972) An investigation of particle trajectories in two-phase flow systems. J Fluid Mech 55(2):193-208

64. Allen MD, Raabe OG (1985) Slip correction measurements of spherical solid aerosol particles in an improved Millikan apparatus. Aerosol Sci Technol 4(3):269-286

65. Lu J et al (2020) COVID-19 outbreak associated with air conditioning in restaurant, Guangzhou, China, 2020. Emerg Infect Dis 26(7): 1628-1631

66. Li Y et al (2020) Evidence for probable aerosol transmission of SARS-CoV-2 in a poorly ventilated restaurant. medRxiv, $p$ 2020.04.16.20067728

67. ANSI/ASHRAE addendum ao to ANSI/ASHRAE standard 62.12019 (2019)

68. Gao N, Niu J (2006) Transient CFD simulation of the respiration process and inter-person exposure assessment. Build Environ 41(9):1214-1222

69. Zhang H, Penninger JM, Li Y, Zhong N, Slutsky AS (2020) Angiotensin-converting enzyme 2 (ACE2) as a SARS-CoV-2 receptor: molecular mechanisms and potential therapeutic target. Intensive Care Med 46(4):586-590

70. Drossinos Y, Stilianakis NI (2020) What aerosol physics tells us about airborne pathogen transmission. Aerosol Sci Technol 54(6):639-643

71. Bourouiba L (2020) Turbulent gas clouds and respiratory pathogen emissions: potential implications for reducing transmission of COVID-19. JAMA 323(18):1837-1838

72. Haghnegahdar A, Zhao J, Feng Y (2019) Lung aerosol dynamics of airborne influenza A virus-laden droplets and the resultant immune system responses: an in silico study. J Aerosol Sci 134:34-55 
73. Birring SS, Matos S, Patel RB, Prudon B, Evans DH, Pavord ID (2006) Cough frequency, cough sensitivity and health status in patients with chronic cough. Respir Med 100(6):1105-1109

74. D B Q sub manual woodworkers: EspoCRM open source community forum. [Online]. https://ba.welake.site/download.php? file $=d+b+q+$ sub + manual + woodworkers. Accessed 28 Apr 2021

75. Bhardwaj R, Agrawal A (2020) Likelihood of survival of coronavirus in a respiratory droplet deposited on a solid surface. Phys Fluids 32(6):061704

76. Tang JW et al (2013) Airflow dynamics of human jets: sneezing and breathing-potential sources of infectious aerosols. PLOS ONE 8(4):1-7

77. Tang JW et al (2012) Airflow dynamics of coughing in healthy human volunteers by shadowgraph imaging: an aid to aerosol infection control. PLOS ONE 7(4):e34818

78. Löhner R, Antil H, Idelsohn S, Oñate E (2020) Detailed simulation of viral propagation in the built environment. Comput Mech 66:1093-1107

79. Antil H (2021) High fidelity modeling of aerosol pathogen propagation in built environments with moving pedestrians. Int J Numer Methods Biomed Eng 37:e3428

80. Wg L et al (2012) Quantity and size distribution of cough-generated aerosol particles produced by influenza patients during and after illness. J Occup Environ Hyg 9(7):443-449

81. Gupta JK, Lin CH, Chen Q (2010) Characterizing exhaled airflow from breathing and talking. Indoor Air 20:31-39

82. Jasak H (2009) OpenFOAM: open source CFD in research and industry. Int J Nav Archit Ocean Eng 1:89-94

83. Yang J, Sekhar SC, Cheong KWD, Raphael B (2015) Performance evaluation of a novel personalized ventilation-personalized exhaust system for airborne infection control. Indoor Air 25(2):176-187

84. Villafruela JM, Olmedo I, De Adana MR, Méndez C, Nielsen PV (2013) CFD analysis of the human exhalation flow using different boundary conditions and ventilation strategies. Build Environ 62:191-200

85. OpenFOAM®: official home of the open source computational fluid dynamics (CFD) Toolbox. [Online]. https://www.openfoam. com/. Accessed 10 Mar 2021

86. Bourouiba L, Dehandschoewercker E, Bush JWM (2014) Violent expiratory events: On coughing and sneezing. J Fluid Mech 745:537-563

87. Sun C, Zhai Z (2020) The efficacy of social distance and ventilation effectiveness in preventing COVID-19 transmission. Sustain Cities Soc 62(July): 102390

88. Wells WF (1955) Airborne contagion and air hygiene. An ecological study of droplet infections. Am J Clin Pathol. https://doi. org/10.1093/ajcp/25.11.1301
89. Riley EC, Murphy G, Riley RL (1978) Airborne spread of measles in a Suburban Elementary School. Am J Epidemiol 107(5):421-432

90. World Health Organization declared a pandemic public health menace: a systematic review of the 'COVID-19', up to 26th March 2020. [Online]. https://www.researchgate.net/publication/ 340379016_World_Health_Organization_declared_a_pandemic_ public_health_menace_A_systematic_review_of_the_COVID19_up_to_26_th_March_2020. Accessed 14 Mar 2021

91. Sohrabi Cet al (2020) World Health Organization declares global emergency: a review of the 2019 novel coronavirus (COVID-19). Int J Surg 76:71-76

92. Dargaville T, Spann K, Celina M (2020) Opinion to address the personal protective equipment shortage in the global community during the COVID-19 outbreak. Polym Degrad Stab 176:109162

93. Weiss MM, Weiss PD, Weiss DE, Weiss JB (2007) Disrupting the transmission of influenza a: face masks and ultraviolet light as control measures. Am J Public Health 97(Suppl 1):S32-S37

94. Hirayama H, Fujikawa S, Kamata N (2015) Recent progress in AlGaN-based deep-UV LEDs. Electron Commun Jpn 98(5):1-8

95. Song K, Mohseni M, Taghipour F (2016) Application of ultraviolet light-emitting diodes (UV-LEDs) for water disinfection: a review. Water Res 94:341-349

96. Taniyasu Y, Kasu M, Makimoto T (2006) An aluminium nitride light-emitting diode with a wavelength of 210 nanometres. Nature 441(7091):325-328

97. Welch D et al (2018) Far-UVC light: a new tool to control the spread of airborne-mediated microbial diseases. Sci Rep $8(1): 2752$

98. Cadet J (2020) Harmless effects of sterilizing 222-nm far-UV radiation on mouse skin and eye tissues. Photochem Photobiol 96(4):949-950

99. Amritsar J, Foroughi S, Raju D, Pakkiriswami S, Packirisamy M (2020) Conformational detection of heat shock protein through bio-interactions with microstructures. Res Biomed Eng 36(1):89-98

100. Liu C, Xu T, Wang D, Zhang X (2020) The role of sampling in wearable sweat sensors. Talanta 212:120801

101. Microfluidics for biotechnology: Jean Berthier, Pascal Silberzan-Google Books. [Online]. https://books.google.com/books? $\mathrm{hl}=$ en\&lr $=\& \mathrm{id}=\mathrm{QTP} 7 \mathrm{pM}-\mathrm{Hc} 78 \mathrm{C} \& \mathrm{oi}=$ fnd $\& \mathrm{pg}=\mathrm{PR} 11 \&$ ots $=$ TbhSjmzXtE\&sig=IbqLs2SSEoLjbtZ7PINTAshZSbk\#v=onepa ge\&q\&f=false. Accessed 02 Apr 2021

102. Sevenler D, Trueb J, Selim Ünlü M (2019) Beating the reaction limits of biosensor sensitivity with dynamic tracking of single binding events. Proc Natl Acad Sci U S A 116(10):4129-4134

Publisher's Note Springer Nature remains neutral with regard to jurisdictional claims in published maps and institutional affiliations. 